\title{
Assimilating bio-optical glider data during a phytoplankton bloom in the southern Ross Sea
}

\author{
Daniel E. Kaufman ${ }^{1}$, Marjorie A. M. Friedrichs ${ }^{1}$, John C. P. Hemmings ${ }^{2, a}$, and Walker O. Smith Jr. ${ }^{1}$ \\ ${ }^{1}$ Virginia Institute of Marine Science, College of William \& Mary, Gloucester Point, VA, USA \\ ${ }^{2}$ Wessex Environmental Associates, Salisbury, UK \\ ${ }^{a}$ now at: Met Office, Exeter, UK
}

Correspondence: Daniel E. Kaufman (dkauf42@gmail.com) and Marjorie A. M. Friedrichs (marjy@vims.edu)

Received: 21 June 2017 - Discussion started: 30 June 2017

Revised: 22 November 2017 - Accepted: 22 November 2017 - Published: 4 January 2018

\begin{abstract}
The Ross Sea is a region characterized by high primary productivity in comparison to other Antarctic coastal regions, and its productivity is marked by considerable variability both spatially $(1-50 \mathrm{~km})$ and temporally (days to weeks). This variability presents a challenge for inferring phytoplankton dynamics from observations that are limited in time or space, which is often the case due to logistical limitations of sampling. To better understand the spatiotemporal variability in Ross Sea phytoplankton dynamics and to determine how restricted sampling may skew dynamical interpretations, high-resolution bio-optical glider measurements were assimilated into a one-dimensional biogeochemical model adapted for the Ross Sea. The assimilation of data from the entire glider track using the micro-genetic and local search algorithms in the Marine Model Optimization Testbed improves the model-data fit by $\sim 50 \%$, generating rates of integrated primary production of $104 \mathrm{~g} \mathrm{Cm}^{-2} \mathrm{yr}^{-1}$ and export at $200 \mathrm{~m}$ of $27 \mathrm{~g} \mathrm{C} \mathrm{m}^{-2} \mathrm{yr}^{-1}$. Assimilating glider data from three different latitudinal bands and three different longitudinal bands results in minimal changes to the simulations, improves the model-data fit with respect to unassimilated data by $\sim 35 \%$, and confirms that analyzing these glider observations as a time series via a one-dimensional model is reasonable on these scales. Whereas assimilating the full glider data set produces well-constrained simulations, assimilating subsampled glider data at a frequency consistent with cruise-based sampling results in a wide range of primary production and export estimates. These estimates depend strongly on the timing of the assimilated observations, due to the presence of high mesoscale variability in this region. Assimilating surface glider data subsampled at a fre-
\end{abstract}

quency consistent with available satellite-derived data results in $40 \%$ lower carbon export, primarily resulting from optimized rates generating more slowly sinking diatoms. This analysis highlights the need for the strategic consideration of the impacts of data frequency, duration, and coverage when combining observations with biogeochemical modeling in regions with strong mesoscale variability.

\section{Introduction}

Phytoplankton blooms in the Ross Sea are responsible for some of the highest rates of productivity in the Southern Ocean (Arrigo et al., 2008), and yet the phytoplankton assemblage exhibits considerable spatiotemporal variability (DiTullio and Smith, 1996; Hales and Takahashi, 2004; Smith et al., 2010). This heterogeneity, and the spatial or temporal limitations of observations due to logistical challenges of sampling, may affect the inferred phytoplankton dynamics and produce biases in productivity or export estimates. The magnitude of the underlying ecosystem variability that contributes to these potential biases is not well understood, nor is it well known how the use of different observational platforms in the Ross Sea might affect the inferred dynamics. Acquiring data with an appropriate resolution is important for assessing phytoplankton variability in the Ross Sea (Hales and Takahashi, 2004).

Over the past several decades, biogeochemistry in the Ross Sea has been observed by ship and satellite, providing data at different temporal and spatial resolutions. Since Ross Sea phytoplankton became a focus of scientific research in the 
late 1970 s, water column measurements have primarily come from research vessels (e.g., El-Sayed et al., 1978; Smith and Nelson, 1985; Vaillancourt et al., 2003). Typically, sampling stations are separated by tens of kilometers (Hales and Takahashi, 2004), and although vessels may return to resample a station, they typically do not return more than once or twice in a single year. During the 1990s, the use of remote sensing was expanded to look more closely at the Ross Sea bloom (Arrigo and McClain, 1994), and satellite retrievals have continued to provide valuable insights into characteristics of the phytoplankton assemblage (Arrigo et al., 1998; Arrigo and van Dijken, 2004; Peloquin and Smith, 2007; Schine et al., 2015). Satellite observations offer a synoptic view of spatial regions at frequencies that are within the timescale of biological changes (e.g., growth); however, the presence of sea ice and clouds often obscures remote-sensing measurements in the Ross Sea (Arrigo et al., 1998).

On the mesoscale (days-weeks, $1-10 \mathrm{~km}$ ), gliders are a relatively new and effective means to characterize phytoplankton variability, and the development of ice-avoidance algorithms has enabled the use of gliders in the Ross Sea for these purposes. For example, a glider equipped with biooptical sensors was directed along a section near $76^{\circ} 40^{\prime} \mathrm{S}$ in austral summer 2010-2011 and provided valuable estimates of biomass variability on short timescales (Kaufman et al., 2014). Estimates of the POC : Chl ratio from the glider optical sensors suggested a transition from a Phaeocystis antarctica ( $P$. antarctica) to a diatom-dominated assemblage over several days (Kaufman et al., 2014; Thomalla et al., 2017). Moreover, Jones and Smith (2017) used glider observations from austral summer 2012-2013 to distinguish three phases of the Ross Sea bloom and identified highfrequency (hours) associations between wind-driven mixing and biomass. A perennial challenge when using glider data (as well as ship-based data), however, is separating the effects of time and space (Kaufman et al., 2014; Little, 2016).

Numerical models are another approach for examining phytoplankton variability in the remote Ross Sea, providing an effective means for coordinating knowledge and understanding the underlying system complexities (Leonelli, 2009; Vallverdú, 2014). Furthermore, numerical simulations offer the possibility for experimental manipulations that would be impractical or impossible in the real system. Such manipulations were implemented in the scenario experiments described by Kaufman et al. (2017a) to investigate how projected climate changes might alter the dynamics of the phytoplankton assemblage. These experiments showed that earlier availability of low light resulting from sea ice reduction was the primary driver of projected increases in production and export and composition change over the next century.

Data assimilation, which refers to methodologies that systematically combine a mathematical model with observations, is often used in biogeochemical applications (Hofmann and Friedrichs, 2001, 2002) to improve estimates of model parameters that are frequently poorly known (Law- son et al., 1995, 1996; Matear, 1995; Fennel et al., 2001; Friedrichs, 2002; Schartau and Oschlies, 2003; Hemmings et al., 2004; Bagniewski et al., 2011; Doron et al., 2013; Xiao and Friedrichs, 2014a, b; Melbourne-Thomas et al., 2015; Song et al., 2016; Gharamti et al., 2017; Schartau et al., 2017). This entails a smoothing or optimization procedure, in which elements of the model are adjusted to minimize differences between the model output and the observations. Typically, an aggregate measure of the differences between observations and model output is provided by calculation of a cost function, defined as the model-data misfit, and an optimization algorithm searches for model parameters that minimize the value of this cost function.

In this study, data assimilation is used to obtain an optimal representation of Ross Sea lower trophic levels. Specifically, observations from an autonomous glider are assimilated into a biogeochemical model of the Ross Sea (Kaufman et al., 2017a) to better understand the spatial and temporal variability in phytoplankton in this region. Assimilation experiments also examine how the space and time characteristics of observational sampling frequency impact the ability of observations to produce optimal system representations.

\section{Methods}

\subsection{One-dimensional biogeochemical model}

Numerical experiments were conducted with the Model of Ecosystem Dynamics, nutrient Utilisation, Sequestration and Acidification for the Ross Sea (MEDUSA-RS; Kaufman et al., 2017a), a regionally adapted version of MEDUSA-1.0 (Yool et al., 2011). Three phytoplankton groups are represented in the MEDUSA-RS model: colonial $P$. antarctica, solitary $P$. antarctica, and diatoms. Phytoplankton growth in the model is temperature dependent as well as limited by light and nutrient availability. Colonial $P$. antarctica, diatoms, and detritus all sink at distinct rates. The model handles the sinking of large detrital particles implicitly as a fastsinking group to avoid issues related to the scale of the model time step and to avoid the need for an additional tracer. A ballast scheme is used to allow inorganic materials to "protect" a variable fraction of the sinking organic material from degradation. The model is configured to focus on dynamics within the euphotic zone with a vertical resolution of $5 \mathrm{~m}$ from the ocean surface to $200 \mathrm{~m}$. A full description of the model and its setup within the Marine Model Optimization Testbed (MarMOT; Hemmings and Challenor, 2012), as well as the physical forcings derived from glider observations, are documented in Kaufman et al. (2017a, b).

\subsection{Data for assimilation}

In situ observations used for the assimilation experiments came from an iRobot Seaglider equipped with a Wet Labs ECO Puck sensor and are available in the Biologi- 


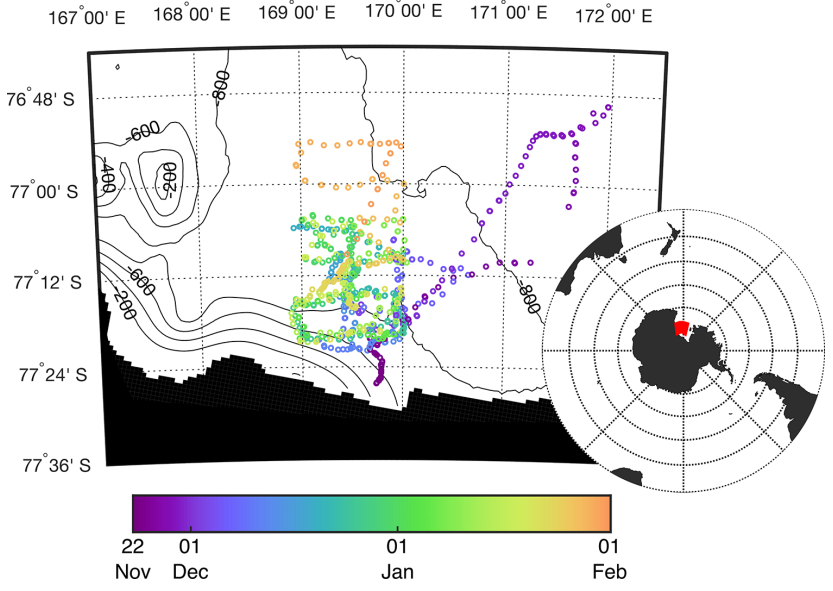

Figure 1. Southern Ross Sea showing transect locations where the glider was at the surface. The color of each glider dive indicates the date. Bathymetric contours are shown at $200 \mathrm{~m}$ intervals, as obtained from the bedmap2 bathymetric data (Fretwell et al., 2013).

cal and Chemical Oceanography Data Management Office data repository (Smith, 2005). Glider dives from 22 November 2012 to 1 February 2013 covered a horizontal area spanning $76.83-77.44^{\circ} \mathrm{S}$ and $168.9-171.97^{\circ} \mathrm{E}$ (Fig. 1). Data spanning the upper $200 \mathrm{~m}$ of the water column were binned by means into hourly, $5 \mathrm{~m}$ vertical bins. Concentrations of chlorophyll (Chl) and particulate organic carbon (POC) were derived, respectively, from fluorescence and optical backscatter counts measured by the sensor and converted using regression equations (Kaufman et al., 2017a). These biooptical quantities were used for calculating model-data misfits during assimilation (Kaufman et al., 2017c).

\subsection{Cost function}

The "cost function" $(J)$, defined as a measure of misfit between a particular model simulation and observational data, is computed as a weighted average of the squared differences between simulated and observed values:

$J=\frac{1}{N} \sum_{i=1}^{N}\left(\frac{1}{\sigma_{\mathrm{chl}}^{2}}\left(x_{i, \mathrm{chl}}-y_{i, \mathrm{chl}}\right)^{2}+\frac{1}{\sigma_{\mathrm{poc}}^{2}}\left(x_{i, \mathrm{poc}}-y_{i, \mathrm{poc}}\right)^{2}\right)$,

where $N$ is the number of observation points, $x_{i}$ is the simulated value of either chlorophyll or POC at the $i$ th observation point, and $y_{i}$ is its observed value; $\sigma$ is the standard deviation (SD) of the specific observation set assimilated in a particular experiment. Using the SD of the observations to define a characteristic scale of variation for each variable is a technique used in previous studies (e.g., Friedrichs et al., 2006; Xiao and Friedrichs, 2014a, b). It is designed to weight the relative misfit contribution of each variable appropriately when there are insufficient data to define a comprehensive error model. Such a model would require reliable information about the uncertainty associated with observation errors (in- strument error and error of representativeness) and nonparametric errors in the simulation such as forcing errors (Schartau et al., 2017). The use of different cost function weighting schemes in plankton modeling, including the characteristic scale technique, is explored in more detail by Hemmings and Challenor (2012).

\subsection{Cost function minimization}

Model parameters were optimized in MarMOT by finding the minimum of the cost function (Sect. 2.3) through a combination of the micro-genetic algorithm $(\mu \mathrm{GA})$ and Powell's non-gradient direction set algorithm. The $\mu \mathrm{GA}$ runs first and identifies sets of parameter values that produce low-cost values; this is achieved by "evolving" a population of various parameter sets over successive iterations, called generations. The low-cost parameter sets identified by the $\mu \mathrm{GA}$ are then used as starting points for the direction set method, which performs successive linear searches to identify nearby lower cost solutions.

Genetic algorithms, including the $\mu \mathrm{GA}$, are a subtype of computational methods known as evolutionary algorithms, so-called because of their inspiration from, and similarity to, biological evolution. Described using this analogy, a genetic algorithm procedure modifies a population of candidate solutions over successive generations by variation and selection processes to converge on a single solution or solution area. Genetic algorithms (GAs) have several advantages for optimization, including their intrinsic parallelism, suitability for systems with multiple local minima, and their generalizability (Bajpai and Kumar, 2010; Ward et al., 2010). The $\mu \mathrm{GA}$ uses three steps to transition from one generation to the next, described following the biological analogy as selection, crossover, and resampling (Krishnakumar, 1990; Črepinšek et al., 2013). An advantage of the $\mu \mathrm{GA}$ is its reduced risk of premature convergence, resulting from re-initializing after each convergence, and generating new random populations while maintaining the best fit individual from the previous set (Schmitt, 2001).

In this $\mu \mathrm{GA}$ implementation, optimizations begin with a population of five individual parameter sets randomly generated for the first $\mu \mathrm{GA}$ generation. The constituent parameter values are selected randomly from within a predetermined range of allowable values (Sect. 2.5.1). An evaluation of the cost function for each model solution indicates the "fitness" of each individual. A binary tournament procedure is then followed to select parents from this population for the next generation. The most-fit individuals (i.e., those with the lowest cost function values) are paired with one another and undergo recombination of the bits representing parameter values. After each generation, the proportion of bits differing from those of the fittest individual is calculated to determine whether the population can be deemed converged (though this does not necessarily indicate closeness in parameter space). After the threshold for convergence has been 
achieved, the population is re-initialized to random individuals, although the fittest individual is maintained. The $\mu \mathrm{GA}$ is terminated upon the first convergence occurring after a minimum number of generations has been reached.

Once convergence has been achieved after a minimum number of $\mu \mathrm{GA}$ generations, Powell's non-gradient direction set algorithm performs a local search using the $\mu \mathrm{GA}$ solutions as starting points. The direction set method performs sequential minimizations in iterative directions, updating the search direction after each iteration (Powell, 1964; Press et al., 1992). Although the $\mu \mathrm{GA}$ is well suited for global search problems partly because of its stochasticity, Powell's direction set algorithm is well suited to searching for a local optimum. Brent's method, which combines root-bracketing with secant and inverse quadratic interpolation (Brent, 1973), is used to numerically locate cost minima between neighboring function evaluations along each direction identified by the Powell algorithm. The direction set algorithm stops when a cost function minimum is located or when a maximum number of iterations is reached. The optimized parameter values are those that generated the cost function minimum.

\subsection{Selection of parameters to be optimized}

Ideally, optimal values are identified for all parameters in a model, however, uncertainty in the parameter estimates from an algorithmic optimization increases as the number of parameters included in that optimization increases (Friedrichs et al., 2007; Ward et al., 2010). Although the optimization of more parameters generally lowers the assimilated cost, the increasing potential for equifinality with more parameters means the optimization may find equivalent lowcost solutions with substantially different parameter values. Therefore, before assimilating observations and optimizing parameters, a subset of "free" or "optimizable" model parameters must be chosen. In this study, the parameters to be optimized are selected through a three-step process: defining a range of permitted values for every parameter (Sect. 2.5.1), identifying the parameters to which model outputs are most sensitive (Sect. 2.5.2), and evaluating how many of these sensitive parameters can be reasonably optimized when assimilating the available data (Sect. 2.5.3). Initial values for each parameter, prior to the assimilation, were set to values identified in Kaufman et al. (2017a).

\subsubsection{Parameter ranges}

Upper and lower bounds of the allowable range for each free parameter were defined loosely following Hemmings et al. (2015). Bounds were set to be geometrically symmetric (factor of 4 for rates; factor of 5 for half-saturation concentrations) around the initial values. For fractional parameter values, limits were set to \pm 0.25 their initial values, although not allowed to exceed 0.05 or 0.95 . Ranges for parameters not expressed as fractions were log-transformed for sampling purposes.

\subsubsection{Sensitivity analysis}

Parameters to which model outputs are highly sensitive are important and useful to optimize. In contrast, it is futile to optimize parameters to which model outputs of interest are not sensitive; no amount of varying these parameters will result in improved model performance. Therefore, the first criterion used to designate a parameter as optimizable was the sensitivity of model outputs to the values of that parameter. Model sensitivities were evaluated for assimilated variables (Chl and POC) and carbon fluxes of interest (primary production (PP) and carbon export at $200 \mathrm{~m}$ ). To quantify the sensitivities of these outputs to each of the 80 parameters in the model, a series of runs were conducted following the approach of Hemmings et al. (2015). Each run used a unique sample of parameter values drawn from within the specified parameter ranges (Sect. 2.5.1) using a Latin hypercube. This approach provides more even coverage of the parameter space than Monte Carlo sampling methods that can result in clustered values and unsampled regions (Appendix A). One thousand values were drawn from sequential intervals throughout the range for each parameter. Using this technique, unique parameter sets were constructed such that over the course of all runs, the full range of values for each parameter was represented.

The model was run 1000 times, each time using one of the unique parameter sets resulting from Latin hypercube sampling of the full parameter space. Sensitivity was quantified by evaluating the amount of variance in the output diagnostics explained by each parameter (i.e., by computing the coefficient of determination $\left(r^{2}\right)$ between each parameter and each of the four output variables of interest; Fig. 2). All four model outputs (Chl, POC, PP, and export) were most sensitive $\left(r^{2} \geq 0.01\right)$ to attenuation of blue-green light by phytoplankton pigments, diatom maximum growth rate, and $\mathrm{C}$ : Chl ratio for solitary $P$. antarctica. Three additional parameters (maximum growth rate of $P$. antarctica colonies, maximum growth rate of solitary $P$. antarctica, and microzooplankton maximum grazing rate) exhibited $r^{2} \geq 0.01$ for both chlorophyll and POC. The 21 parameters with $r^{2} \geq 0.01$ (Fig. 2) were selected for further evaluation (Sect. 2.5.3).

\subsubsection{Using twin experiments to select optimizable subset}

After selecting the 21 potentially optimizable parameters, numerical twin experiments (NTEs) were conducted to identify an optimizable subset by evaluating the extent to which known values of sensitive parameters could be recovered given the data available for assimilation. The implementation of NTEs involves four primary steps (Hofmann and Friedrichs, 2001). First, the chosen model is run forward in 


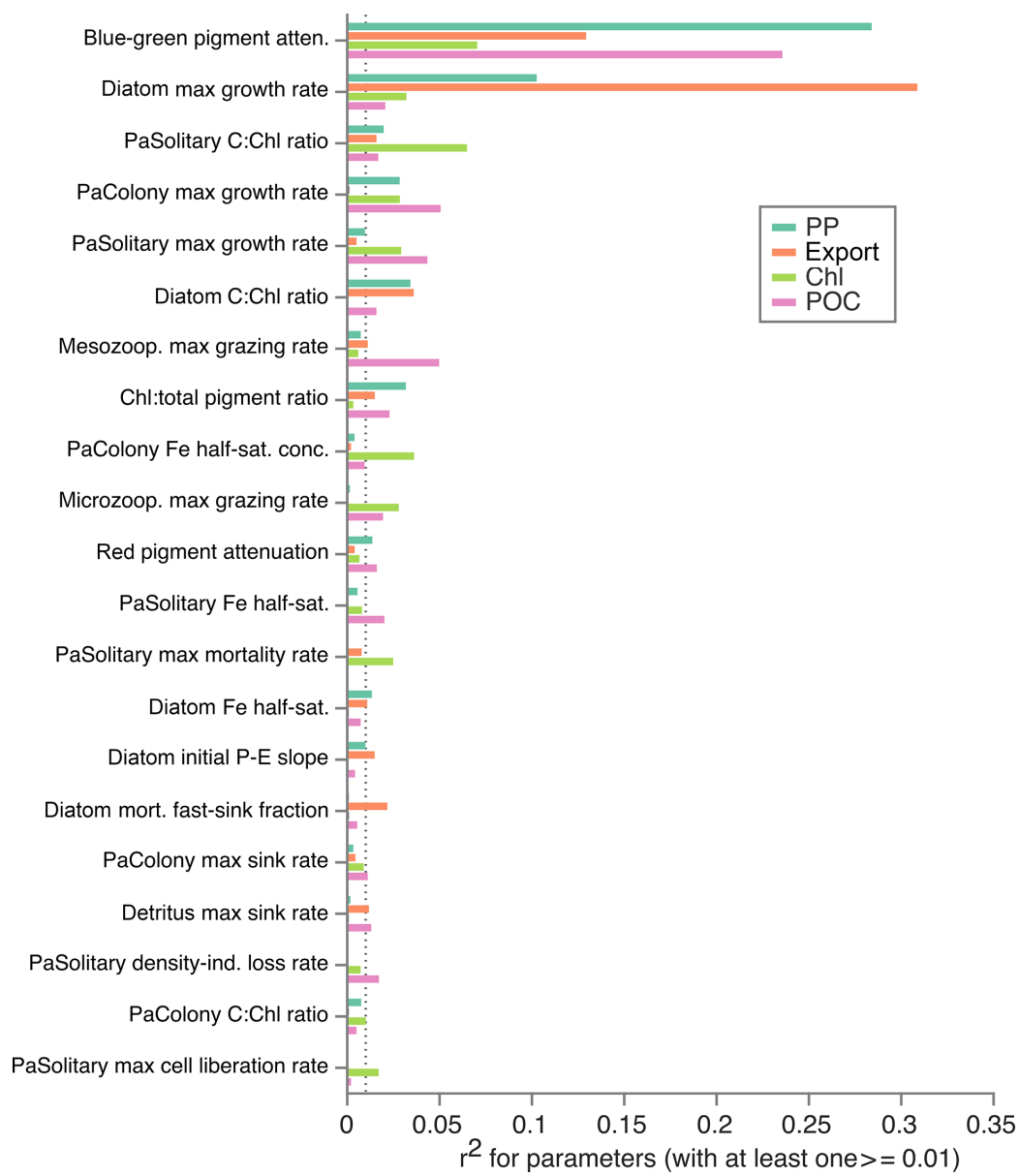

Figure 2. Variance explained in model outputs by parameters during sensitivity tests using Latin hypercube sampling of parameter space. Only parameters with at least one $r^{2}$ value greater than or equal to 0.01 (vertical dotted line) are shown.

time to create a simulation using a known, "true" parameter set. Second, output from this simulation is subsampled to create a so-called "synthetic" data set. Third, the synthetic dataset is then assimilated to optimize model parameters. Fourth, the optimized parameter set is compared to the true parameter set. The assimilation is successful if the optimized values recover the true parameters used to generate the assimilated synthetic data.

There is a limit to the number of parameters that can be independently constrained by the available observations because varying different parameters can often have similar effects on the cost function. Optimizing a larger set increases the potential for correlation between the effects of different parameters, reducing the algorithm's effectiveness in identifying unique optimal parameter sets. This, combined with the increased potential for over-fitting associated with the greater model degrees of freedom, can reduce the ability of an optimized model to reproduce independent data (Matear, 1995; Friedrichs et al., 2007; Xiao and Friedrichs et al., 2014b). The limitation on the number of optimizable parameters applies to both $\mu \mathrm{GA}$ and variational adjoint optimiza- tions (Ward et al., 2010). In fact, rather than being a function of the optimization algorithm, it is dependent on the available data and the design of the cost function (Löptien and Dietze, 2015). A larger or richer observation set can help to constrain more parameters. The impact of cost function design is more complicated because an improved cost function may allow for greater uncertainty in the observations and/or nonparametric uncertainty in the simulation, leading to weaker but more realistic constraints on the parameters (Hemmings and Challenor, 2012).

The procedure followed here for determining the subset of optimizable parameters is similar to that used by Friedrichs et al. (2007). First, a reference simulation was generated using the initial parameter set, and chlorophyll and POC estimates from this reference simulation were subsampled to generate a synthetic data set. Starting with a parameter space defined by the set of 21 parameters deemed sensitive in the Latin hypercube tests (Fig. 2), a series of sequential NTEs was then performed with a progressively smaller number of optimized parameters: after each NTE, the optimized parameter that was most different from its "true" value was re- 

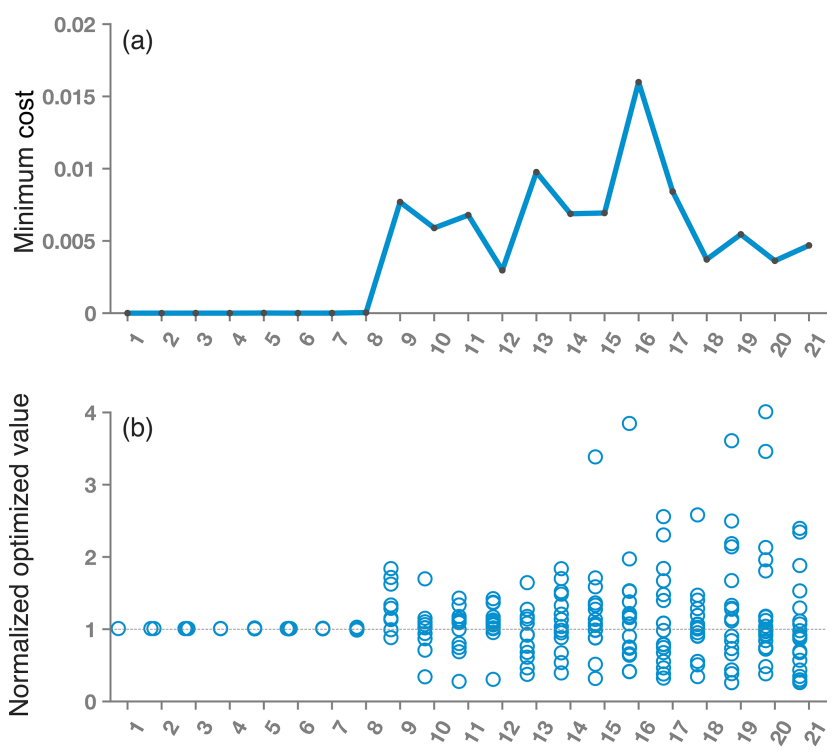

No. of free parameters

Figure 3. (a) Minimum costs and (b) normalized parameter values in numerical twin experiments, illustrating that the assimilation procedure is unable to successfully recover the true parameter values when more than eight parameters are optimized. One data point in three of the experiments $(19,20$, and 21) exceeds the $y$ axis upper limit in panel (b).

moved from the optimizable parameter set. Thus, after each NTE the number of optimized parameters was reduced by one. The series of NTEs was evaluated to identify the largest parameter set for which the original parameter values were recoverable and for which the cost function remained essentially 0. From this analysis (Fig. 3), it was determined that optimizing eight parameters would be ideal (Table 1) because values of these eight parameters were recovered much better than larger parameter sets and model-data misfit (cost) remained low.

\subsection{Assimilation experiments}

The $\mu$ GA optimization procedure was used to assimilate glider data in two sets of experiments that explored aspects of spatiotemporal variability and data availability. Estimates of depth- and time-integrated PP and time-integrated carbon export at $200 \mathrm{~m}$ were computed from the full model simulation in each experiment.

\subsubsection{Experiment 1}

The first set of experiments examined the differences in model simulations resulting from assimilating $\mathrm{Chl}$ and POC data from different spatial regions. In Experiment 1a, glider observations were assimilated from the upper $50 \mathrm{~m}$ of the full temporal and spatial domain, referred to hereafter as the "Full Assimilation" case (Table 2). (Comparisons showed only minor differences between assimilating data from the upper $50 \mathrm{~m}$ vs. the full upper $200 \mathrm{~m}$.) Observations from different spatial areas of the glider track were also assimilated. Observations from the glider track were divided into three latitudinal bands (northern, central, and southern bands) as well as into three longitudinal areas constituting eastern, central, and western bands. Glider data from each of these three latitudinal and longitudinal bands were assimilated in Experiments $1 \mathrm{~b}$ and $1 \mathrm{c}$, respectively (Table 2, Fig. 4), resulting in three cost functions for each of these experiments.

\subsubsection{Experiment 2}

The second set of experiments investigated the assimilation of data at different resolutions mimicking different data sources. In Experiment 2a, glider data were subsampled at $\sim 12 \mathrm{~h}$ intervals (Table 2 ). The subsampling was repeated 12 times, with each iteration offset from the previous by +1 , $2,3, \ldots 11 \mathrm{~h}$, to generate a series of 12 glider observation sets. The assimilation of these 12 time series yields the "Glider Assimilation" case. In Experiment 2b, glider data were subsampled at a reduced temporal resolution similar to cruise sampling (Table 2). Sampling during cruise missions often takes place for a few days in one location before moving elsewhere, and the ship sometimes returns to the first location after a number of weeks. To roughly mimic this sampling pattern, daily vertical profiles (again down to $50 \mathrm{~m}$ ) were assimilated for 3 days in a row, starting from the first day of available glider data (22 November), and then 3 days of data were assimilated 2 weeks later. Shifting this pattern forward 1 week at a time generated a series of eight cruise-based observation sets for assimilation in this "Cruise-Based Assimilation" case. In Experiment 2c, glider data were assimilated only from the upper $5 \mathrm{~m}$ surface layer to produce a data set resembling satellite-derived data. These data were then subsampled at 2-week intervals, to represent typical data return from remote-sensing observations of ocean color in the Ross Sea, where the availability of satellite image retrieval is frequently limited by excessive, though variable, cloud cover (Arrigo and van Dijken, 2004). The 2 -week subsampling pattern covered the entire period of glider data (22 November1 February) and was sequentially shifted forward 1 day at a time to generate a series of 14 satellite-based observation sets for assimilation in this "Satellite-Based Assimilation" case (Table 2).

\subsection{Predictive cost assessment}

In addition to the assimilative cost $\left(J_{\mathrm{A}}\right)$ calculated during the optimization procedure using assimilated data, a predictive cost $\left(J_{\mathrm{P}}\right)$ was calculated to assess model-data misfit computed using the unassimilated data in each experiment. Because predictive costs represent model-data misfit from unassimilated data only (Friedrichs et al., 2006; Ward et al., 2010), it is an objective measure of the skill of an optimized 
Table 1. Eight parameters optimized in this analysis.

\begin{tabular}{lll}
\hline Parameter name & $\begin{array}{l}\text { Initial value } \\
\text { (Kaufman et al., 2017a) }\end{array}$ & $\begin{array}{l}\text { Bounds } \\
\text { (lower, upper) }\end{array}$ \\
\hline $\begin{array}{l}\text { Diatom max. growth rate at } 0^{\circ} \mathrm{C} \\
P . \text { antarctica } \text { solitary cells } \mathrm{C}: \mathrm{Chl} \text { ratio }\end{array}$ & $0.375\left(\mathrm{~d}^{-1}\right)$ & $0.09375,1.5$ \\
$P$. antarctica colonies max. growth rate at $0^{\circ} \mathrm{C}$ & $30\left(\mathrm{~g} \mathrm{CgCh}^{-1}\right)$ & $7.5,120$ \\
$P$. antarctica solitary cells max. growth rate at $0^{\circ} \mathrm{C}$ & $0.5\left(\mathrm{~d}^{-1}\right)$ & $0.125,2$ \\
Diatom C $:$ Chl ratio & $150\left(\mathrm{~g} \mathrm{Cg} \mathrm{Chl}^{-1}\right)$ & $0.125,2$ \\
Fast detritus sinking fraction of diatom losses & 0.75 & $37.5,600$ \\
$P$. antarctica colonies max. sinking rate & $20\left(\mathrm{~m} \mathrm{~d}^{-1}\right)$ & $0.5,0.95$ \\
$P$. antarctica colonies $\mathrm{C}:$ Chl ratio & $40\left(\mathrm{gCgChl}^{-1}\right)$ & 5,80 \\
\hline
\end{tabular}

$167^{\circ} 00^{\prime} \mathrm{E} \quad 168^{\circ} 00^{\prime} \mathrm{E} \quad 169^{\circ} 00^{\prime} \mathrm{E} \quad 170^{\circ} 00^{\prime} \mathrm{E} \quad 171^{\circ} 00^{\prime} \mathrm{E} \quad 172^{\circ} 00^{\prime} \mathrm{E}$

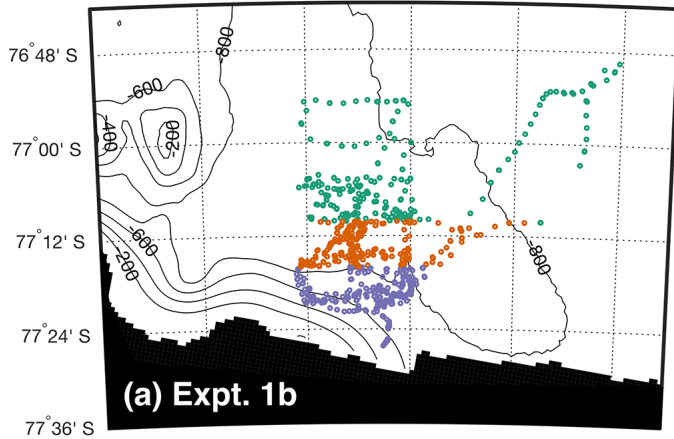

North band Central band South band $167^{\circ} 00^{\prime} \mathrm{E} \quad 168^{\circ} 00^{\prime} \mathrm{E} \quad 169^{\circ} 00^{\prime} \mathrm{E} \quad 170^{\circ} 00^{\prime} \mathrm{E} \quad 171^{\circ} 00^{\prime} \mathrm{E} \quad 172^{\circ} 00^{\prime} \mathrm{E}$

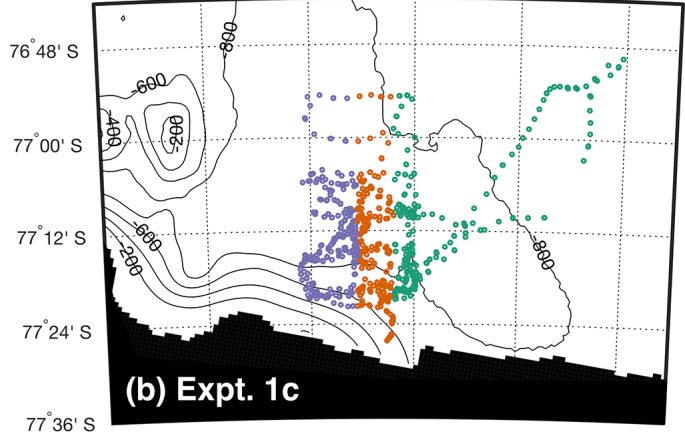

East band Central band West band

Figure 4. Locations of glider observations assimilated in (a) Experiment 1b - latitudinal bands - and (b) Experiment 1c - longitudinal bands . Colors represent the three spatial bands of data assimilated.

model in reproducing observations at different points in time or space (Gregg et al., 2009). In this case, the aim of these experiments is to assess the skill of each optimized simulation regardless of which subset of the available data is assimilated. By computing the mean and median predictive cost for each experiment (other than the Full Assimilation case), the skill of the resulting simulations can be compared directly with one another.

\section{Results}

\subsection{Experiment 1}

The assimilation of the glider data over the full temporal and spatial domain (Full Assimilation case) improves the modeldata fit of both $\mathrm{Chl}$ and POC (Fig. 5a and b) and reduces the cost by nearly half ( $47 \%$ ) compared to the a priori simulation without assimilation (No Assimilation case; Table 3). Average $\mathrm{Chl}$ and POC concentrations in the upper $50 \mathrm{~m}$ are both slightly lower (8 and 12\%, respectively) in the optimized simulation. The contribution of each phytoplankton group to total chlorophyll remains similar to the No Assimilation case (Fig. 6a and c), but colonial P. antarctica carbon is lower and diatom carbon is higher in December and early January (Fig. 6b and d). Compared to the No Assimilation case, PP is only slightly lower (7\%), whereas export flux is nearly $50 \%$ higher (Table 3; Fig. 7). Compared to their initial values, colonial $P$. antarctica parameters change the most as a result of the optimization, with reductions between 40 and $70 \%$ for the colonial $P$. antarctica maximum growth rate, maximum sinking rate, and $\mathrm{C}: \mathrm{Chl}$ ratio (Table 4$)$. In contrast, the diatom maximum growth rate and $\mathrm{C}: \mathrm{Chl}$ ratio increased ( $\sim 10$ and $20 \%$, respectively).

Chlorophyll and POC time series exhibit only minor differences between latitudinal band experiments when data from the northern, central, and southern sections are assimilated independently (Fig. 5c and d) or when data from the eastern, central, and western sections are assimilated (Fig. 5e and f). Specifically, the optimal simulations for $\mathrm{Chl}$ and POC exhibit similar seasonal cycles across the three latitudinal and longitudinal bands, with only slightly higher $\mathrm{Chl}$ and POC concentrations when assimilating data from the southern band (Fig. 5c and d) and higher Chl from the western band (Fig. 5e and f). Mean costs are much lower for the latitudinal and longitudinal experiments than for the No Assimilation case, and only slightly higher than the Full As- 
Table 2. Spatiotemporal resolution of glider-based observations of Chl and POC assimilated for each experiment.

\begin{tabular}{|c|c|c|c|}
\hline Experiment & $\begin{array}{l}\text { Depth } \\
(\mathrm{m})\end{array}$ & Temporal resolution & Spatial area(s) \\
\hline Expt 1a: Full Assimilation & $0-50$ & Hourly & Full glider track \\
\hline Expt 1b: Latitudinal Assimilation & $0-50$ & Hourly & North, central, south latitudinal bands \\
\hline Expt 1c: Longitudinal Assimilation & $0-50$ & Hourly & East, central, west longitudinal bands \\
\hline Expt 2a: Glider Assimilation & $0-50$ & $\begin{array}{l}\sim \text { twice per day, separated at a } \\
\text { minimum of } 12 \mathrm{~h} .\end{array}$ & Full glider track \\
\hline Expt 2b: Cruise-Based Assimilation & $0-50$ & $\begin{array}{l}3 \text { days in a row, and then another } 3 \\
\text { consecutive days } 2 \text { weeks later }\end{array}$ & Full glider track \\
\hline Expt 2c: Satellite-Based Assimilation & $0-5$ & 1 day every 2 weeks & Full glider track \\
\hline
\end{tabular}
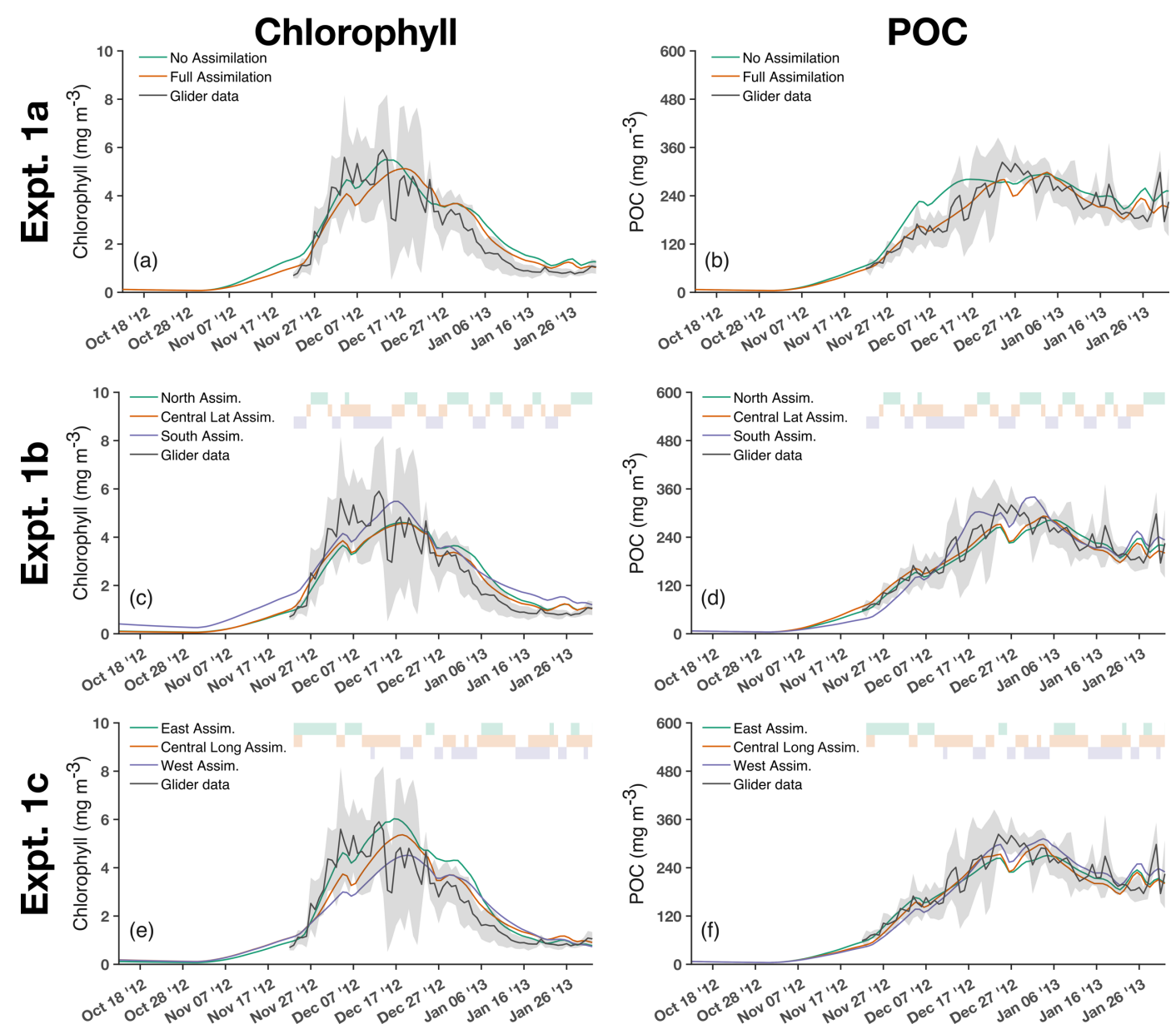

Figure 5. Upper $50 \mathrm{~m}$ mean concentrations of (a, c, e) Chl and (b, d, f) POC for various experiments assimilating the full glider and from different spatial areas (Table 2): (a, b) Experiment 1a, (c, d) Experiment 1b - latitude bands - and (e, f) Experiment 1c - longitude bands. For reference, glider data (black lines) with shading (gray) representing $1 \mathrm{SD}$ (from the upper $50 \mathrm{~m}$ ) are included in each panel. Colored boxes at the top of each panel indicate times of assimilated observations.

similation case (Table 3). This indicates that data sampled from within only one spatial band improved the match between modeled and observed variables in the unassimilated areas as well. Average estimates of PP and export in both the latitudinal and longitudinal experiments are only slightly less $(<5 \%)$ than the Full Assimilation estimate (Fig. 7, Table 3).

\subsection{Experiment 2}

The assimilation of data subsampled at a frequency $1 / 12$ that of the original glider data (Experiment 2a) results in 12 model simulations, all of which are similar to the Full Assimilation case, with $\mathrm{Chl}$ and POC time series closely fol- 

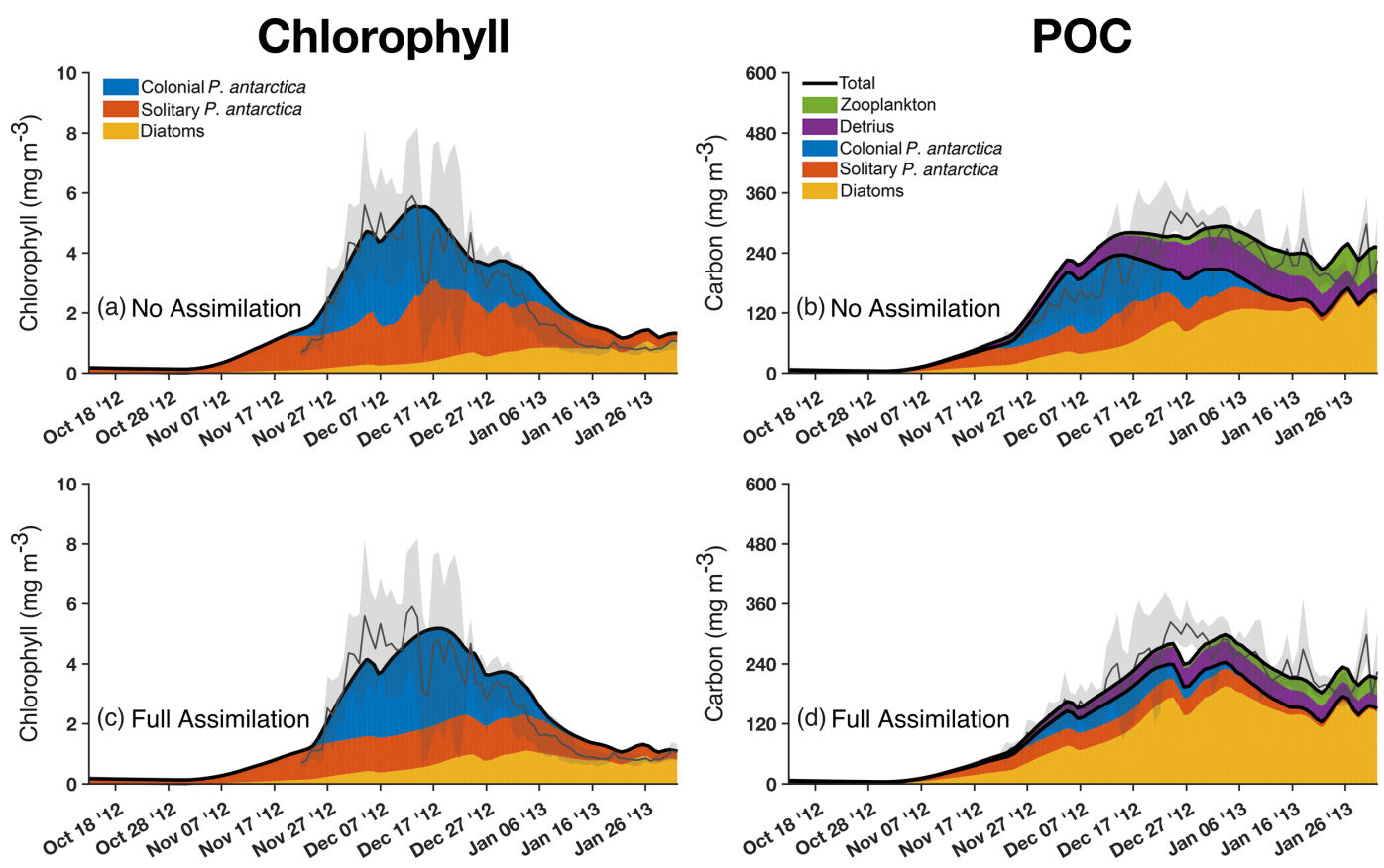

Figure 6. Upper $50 \mathrm{~m}$ mean concentrations of the three phytoplankton groups in terms of (a, c) Chl and (b, d) POC for the No Assimilation case (a, b) and the Full Assimilation case (c, d). The glider data are shown (black line) with shading (gray) that represents 1 SD daily.

Table 3. Depth- and time-integrated (over the length of the simulation, representing yearly rates) primary production (PP), carbon export flux at $200 \mathrm{~m}$, and costs for the No Assimilation run (cost: 0.77), Experiment 1, and Experiment 2. Costs provide a measure of the misfit between a particular model simulation and observations, and the costs shown represent mean $\pm 1 \mathrm{SD}$ of assimilative runs. The assimilative and predictive costs are computed from the assimilated and unassimilated data, respectively.

\begin{tabular}{lllll}
\hline Simulation name & $\begin{array}{l}\mathrm{PP} \\
\left(\mathrm{g} \mathrm{C} \mathrm{m}^{-2} \mathrm{yr}^{-1}\right)\end{array}$ & $\begin{array}{l}\text { Export } \\
\left(\mathrm{g} \mathrm{Cm}^{-2} \mathrm{yr}^{-1}\right)\end{array}$ & $\begin{array}{l}\text { Predictive } \\
\operatorname{cost}\left(J_{\mathrm{P}}\right)\end{array}$ & $\begin{array}{l}\text { Assimilation } \\
\operatorname{cost}\left(J_{\mathrm{A}}\right)\end{array}$ \\
\hline No Assimilation & 111.7 & 18.8 & - & - \\
Expt 1a: Full Assimilation & 104.2 & 27.2 & - & 0.41 \\
Expt 1b: Latitudinal Assimilation & $101.8 \pm 3.3$ & $26.1 \pm 2.1$ & $0.49 \pm 0.13$ & $0.43 \pm 0.14$ \\
Expt 1c: Longitudinal Assimilation & $103.2 \pm 2.1$ & $26.9 \pm 2.1$ & $0.50 \pm 0.10$ & $0.46 \pm 0.13$ \\
Expt 2a: Glider Assimilation & $103.7 \pm 1.8$ & $27.0 \pm 1.2$ & $0.43 \pm 0.01$ & $0.43 \pm 0.03$ \\
Expt 2b: Cruise-Based Assimilation & $113.1 \pm 22.3$ & $24.8 \pm 6.6$ & $1.24 \pm 0.95$ & $0.52 \pm 0.19$ \\
Expt 2c: Satellite-Based Assimilation & $114.1 \pm 10.7$ & $16.7 \pm 2.7$ & $1.04 \pm 0.36$ & $0.26 \pm 0.16$ \\
\hline
\end{tabular}

lowing the observed seasonal pattern (Fig. 8a and b). Mean assimilative and predictive costs in the Glider Assimilation case are close to the cost of the Full Assimilation case (Table 3). Mean PP and export estimates are also close to estimates from the Full Assimilation case. The mean optimal parameter values obtained from the Glider Assimilation case are generally within $1 \mathrm{SD}$ of the optimal values from the Full Assimilation case (Table 4).

The assimilation of data subsampled with a frequency typical of cruise observations (Experiment $2 \mathrm{~b}$ ) results in a wide range of solutions, with several $\mathrm{Chl}$ and POC time series exhibiting markedly different peak bloom timings (Fig. 8c and d). Two of the solutions yield substantially higher concentrations of POC in November, and Chl peaks range from mid-November to early January. The mean predictive cost from this experiment (1.24) is roughly 3 times the assimilative cost for the Full Assimilation case (0.41) and 3 times the predictive cost for the Glider Assimilation case (0.43; Table 3). The PP estimates from the Cruise-Based Assimilation case span a broad range ( 92 to $156 \mathrm{~g} \mathrm{Cm}^{-2} \mathrm{yr}^{-1}$ ) around the Full Assimilation estimate but are generally higher (Fig. 7a). This experiment similarly yields a very large range of export estimates ( 11 to $33 \mathrm{~g} \mathrm{C} \mathrm{m}^{-2} \mathrm{yr}^{-1}$ ) encompassing the results from Experiment 1 (Fig. 7b). Optimal parameter values obtained from the Cruise-Based Assimilation case are generally less well constrained (higher SDs) than the Glider Assimilation case (Table 4). 
Table 4. Initial parameter values (No Assimilation) and optimal parameter values after conducting the Full Assimilation, Glider Assimilation, Cruise-Based Assimilation, and Satellite-Based Assimilation experiments.

\begin{tabular}{|c|c|c|c|c|c|}
\hline Parameter name & $\begin{array}{l}\text { Initial } \\
\text { value }\end{array}$ & $\begin{array}{l}\text { Expt 1a } \\
\text { Full } \\
\text { Assimilation }\end{array}$ & $\begin{array}{l}\text { Expt 2a } \\
\text { Glider* }\end{array}$ & $\begin{array}{l}\text { Expt 2b } \\
\text { Cruise- } \\
\text { Based* }\end{array}$ & $\begin{array}{l}\text { Expt 2c } \\
\text { Satellite- } \\
\text { Based* }^{*}\end{array}$ \\
\hline $\begin{array}{l}\text { Diatom max. growth rate at } 0^{\circ} \mathrm{C} \\
\left(\mathrm{d}^{-1}\right)\end{array}$ & 0.375 & 0.40 & $0.43 \pm 0.01$ & $0.42 \pm 0.15$ & $0.41 \pm 0.09$ \\
\hline $\begin{array}{l}\text { P. antarctica solitary cells } \\
\text { C: Chl ratio }\left(\mathrm{g} \mathrm{CgChl}^{-1}\right)\end{array}$ & 30 & 29.7 & $25.84 \pm 5.16$ & $37.3 \pm 26.7$ & $51.5 \pm 26.8$ \\
\hline $\begin{array}{l}\text { P. antarctica colonies } \\
\text { max. growth rate at } 0^{\circ} \mathrm{C}\left(\mathrm{d}^{-1}\right)\end{array}$ & 0.5 & 0.29 & $0.22 \pm 0.10$ & $0.45 \pm 0.58$ & $0.29 \pm 0.17$ \\
\hline $\begin{array}{l}\text { P. antarctica solitary cells max. } \\
\text { growth rate at } 0^{\circ} \mathrm{C}\left(\mathrm{d}^{-1}\right)\end{array}$ & 0.5 & 0.39 & $0.45 \pm 0.06$ & $0.75 \pm 0.70$ & $0.79 \pm 0.51$ \\
\hline $\begin{array}{l}\text { Diatom C: Chl ratio } \\
\left(\mathrm{gCgCh}^{-1}\right)\end{array}$ & 150 & 176.4 & $166.6 \pm 50.17$ & $252.4 \pm 164.28$ & $374.86 \pm 187.82$ \\
\hline $\begin{array}{l}\text { Fast detritus sinking fraction of } \\
\text { diatom losses }\end{array}$ & 0.75 & 0.87 & $0.86 \pm 0.05$ & $0.86 \pm 0.11$ & $0.62 \pm 0.14$ \\
\hline $\begin{array}{l}\text { P. antarctica colonies max. } \\
\text { sinking rate }\left(\mathrm{m} \mathrm{d}^{-1}\right)\end{array}$ & 20 & 10.7 & $10.1 \pm 3.66$ & $20.1 \pm 20.5$ & $12.8 \pm 9.27$ \\
\hline $\begin{array}{l}\text { P. antarctica colonies } \\
\text { C: Chl ratio }\left(\mathrm{gCgChl}^{-1}\right)\end{array}$ & 40 & 14.0 & $14.2 \pm 2.29$ & $42.7 \pm 41.6$ & $34.3 \pm 26.5$ \\
\hline
\end{tabular}

$*$ Mean \pm 1 SD of assimilative runs.

The assimilation of data subsampled as satellite-based observations from the surface layer (Experiment 2c) results in $\mathrm{Chl}$ and POC concentrations generally higher than the Full Assimilation case (Fig. 8e and f). The predictive costs are similar on average to those of the Cruise-Based Assimilation experiment; however, there is less variation (Table 3). The median integrated production is higher $(9 \%)$ than the Full Assimilation estimate and the Cruise-Based Assimilation estimate (Fig. 7a; Table 3); however, the range of PP estimates for this Satellite-Based Assimilation case is smaller than those for the Cruise-Based Assimilation case (Fig. 7a). Most notably, despite generally higher PP and higher POC concentrations, carbon export from the Satellite-Based Assimilation case is substantially lower (41\%) than the Full Assimilation estimate (Fig. 7b; Table 3). In fact, export estimates from individual runs in this experiment are all lower ( -19 to $-56 \%$ ) than the Full Assimilation estimate (Fig. 7b). Again, the range of export estimates is smaller for the SatelliteBased Assimilation than for the Cruise-Based Assimilation. When assimilating data at a resolution similar to that of satellite-based observations, mean optimal parameter values were similar to those obtained in the Glider Assimilation and Cruise-Based Assimilation cases, with the exception of the fast detritus sinking fraction for diatoms, which was significantly lower in the Satellite-Based Assimilation case $(0.62 \pm 0.14)$ than in the other experiments (Glider Assimilation Case: $0.86 \pm 0.05$ ). In contrast to this sinking parameter for mortality from diatoms, the mean maximum sinking rate of colonial P. antarctica in the Satellite-Based Assimilation case was not significantly different than its value in either the Full Assimilation or Cruise-Based Assimilation cases (Table 4). Standard deviations of optimal parameters for the Satellite-Based Assimilation case were generally similar to or lower than those for the Cruise-Based Assimilation case, except for the $\mathrm{C}$ : $\mathrm{Chl}$ ratio for diatoms, which produced a very high optimal value and was particularly poorly constrained $\left(375 \pm 187 \mathrm{~g} \mathrm{Cg} \mathrm{Chl}^{-1}\right.$; Table 4).

\section{Discussion}

\subsection{Ross Sea simulation resulting from the assimilation of glider data}

Data assimilation is a valuable tool for efficiently utilizing limited observational data in remote regions like the Ross Sea. In this study, glider data consisting of both fluorescencederived chlorophyll and backscatter-derived POC were assimilated into a one-dimensional marine biogeochemical model developed for the Ross Sea. Eight ecosystem parameters, including phytoplankton growth and sinking rates and $\mathrm{C}: \mathrm{Chl}$ ratios, were optimized resulting in a simulation with a 50\% reduced model-data misfit. This Full Assimilation run yielded lower $P$. antarctica carbon concentrations and higher diatom carbon concentrations, resulting in higher carbon export compared to those generated by the No Assimilation run (Kaufman et al., 2017a), despite slightly lower estimates of overall annual primary production. Changes in chlorophyll concentrations of diatoms and $P$. antarctica were minor. This Full Assimilation simulation was obtained largely via changes in the $\mathrm{C}: \mathrm{Chl}$ ratios: the colonial $P$. antarc- 

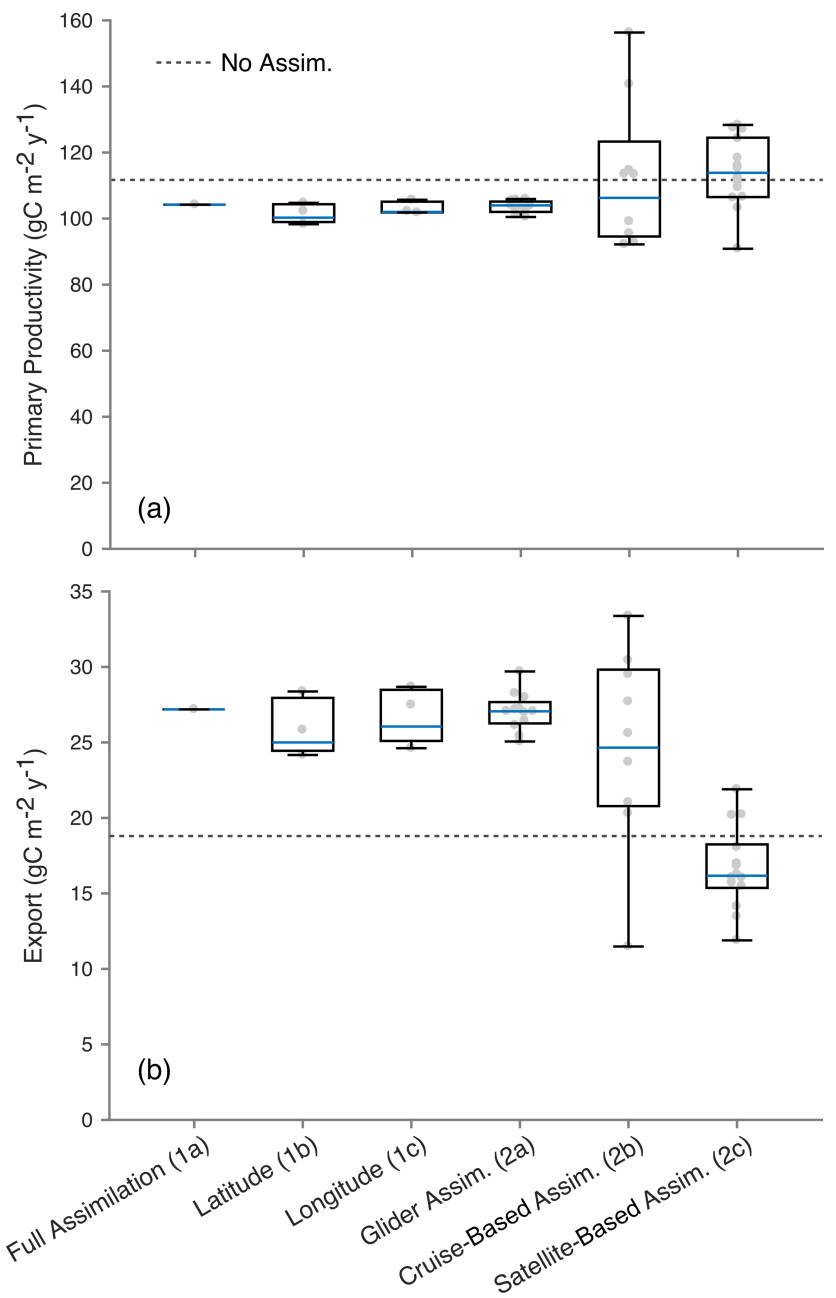

Figure 7. Distributions of (a) depth- and time-integrated production and (b) carbon export flux at $200 \mathrm{~m}$ for each assimilation experiment (Table 2). The median value for each experiment is indicated by a horizontal light-blue line. Each box extends vertically from the first to third quartile, and the whiskers extend from the lowest to highest values. Individual values are shown as gray dots. For reference, production and export estimates from the No Assimilation (dashed gray line) case is included in each panel.

tica ratio of $\mathrm{C}$ : $\mathrm{Chl}$ was lower and the diatom $\mathrm{C}: \mathrm{Chl}$ was higher than in the original simulation. Although modified from their initial values, the relative differences between these optimized $\mathrm{C}: \mathrm{Chl}$ ratios for $P$. antarctica and diatoms are consistent with shipboard measurements of $\mathrm{C}: \mathrm{Chl}$ ratios, which found higher $\mathrm{C}: \mathrm{Chl}$ in diatom-dominated waters compared to $P$. antarctica-dominated waters: $\sim 200$ vs. $90 \mathrm{~g} \mathrm{Cg} \mathrm{Chl}^{-1}$ (DiTullio and Smith, 1996) and $\sim 50-100$ vs. 20-50 $\mathrm{g} \mathrm{CgChl}^{-1}$ (Mathot et al., 2000). Although the authors are not aware of any specific estimates in the literature for the fraction of diatom mortality that becomes fastsinking detritus, other optimal rate parameters are consistent with those previously reported in the literature. For exam- ple, the optimized growth rates $\left(0.29-0.4 \mathrm{~d}^{-1}\right)$ are similar to measured values in the Ross Sea (Smith and Gordon, 1997; Smith et al., 1999; Mosby and Smith, 2015), and the optimized sinking rate of $P$. antarctica colonies $\left(14 \mathrm{md}^{-1}\right)$ is similar to previous estimates (Asper and Smith, 1999, 2003; Smith et al., 2011).

The high number of model evaluations in each optimization case (roughly 4000-5000) makes such direct optimization impractical for large-scale models; however, the parameters identified in a 1-D model by these techniques can be used in larger models, and indeed locally optimized parameters have been previously shown to improve the skill of 3-D models in other regions (Oschlies and Schartau, 2005; Kane et al., 2011; McDonald et al., 2012; St-Laurent et al., 2017). It is expected that the optimized parameter values found in the one-dimensional assimilation experiments described here will be of value in a future 3-D biogeochemical modeling analysis of the Ross Sea and, through model intercomparisons, provide a basis for examining the dependence of these parameter values on model structure and level of complexity, as has been done elsewhere (Friedrichs et al., 2007; Bagniewski et al., 2011; Ward et al., 2013; Irby et al., 2016).

\subsection{Spatial variation within the glider track}

Phytoplankton in the Ross Sea exhibit both spatial and temporal variability. Cruise transects across the continental shelf show a marked spatial variability in both the east-west and north-south direction over short periods of time (Smith et al., 2013). Within the Ross Sea polynya, ship-based observations show biochemical gradients that suggest patchiness of phytoplankton dynamics on the mesoscale (Hales and Takahashi, 2004; Smith et al., 2017). Nutrient pools have been found to exhibit gradients from both north to south and east to west (DiTullio and Smith, 1996; Sedwick et al., 2011; Smith et al., 2013; Marsay et al., 2014), and phytoplankton assemblage composition is not necessarily uniform across longitudes (DiTullio and Smith, 1996; Garrison et al., 2003; Smith et al., 2013). In addition, cold and fresh eddies have been observed along the ice shelf edge potentially reshaping the phytoplankton assemblage on short timescales ( $<10$ days) and space $(<20 \mathrm{~km})$ scales (Li et al., 2017).

When analyzing glider data in regions characterized by high mesoscale variability, it is often not apparent whether observed patterns represent spatial or temporal variability. As Rudnick (2016) discusses, "because gliders can occupy lines, their data can be viewed as traditional sections, such as those measured from a ship. However, because highfrequency variability is projected onto a spatial structure, it is sometimes more convenient to think of the data as a time series from a mooring." This ambiguity led Kaufman et al. (2014) to concede "both spatial and temporal gradients may have played a role in the observed variability" when analyzing physical-biological relationships from glider data in the southern Ross Sea. 

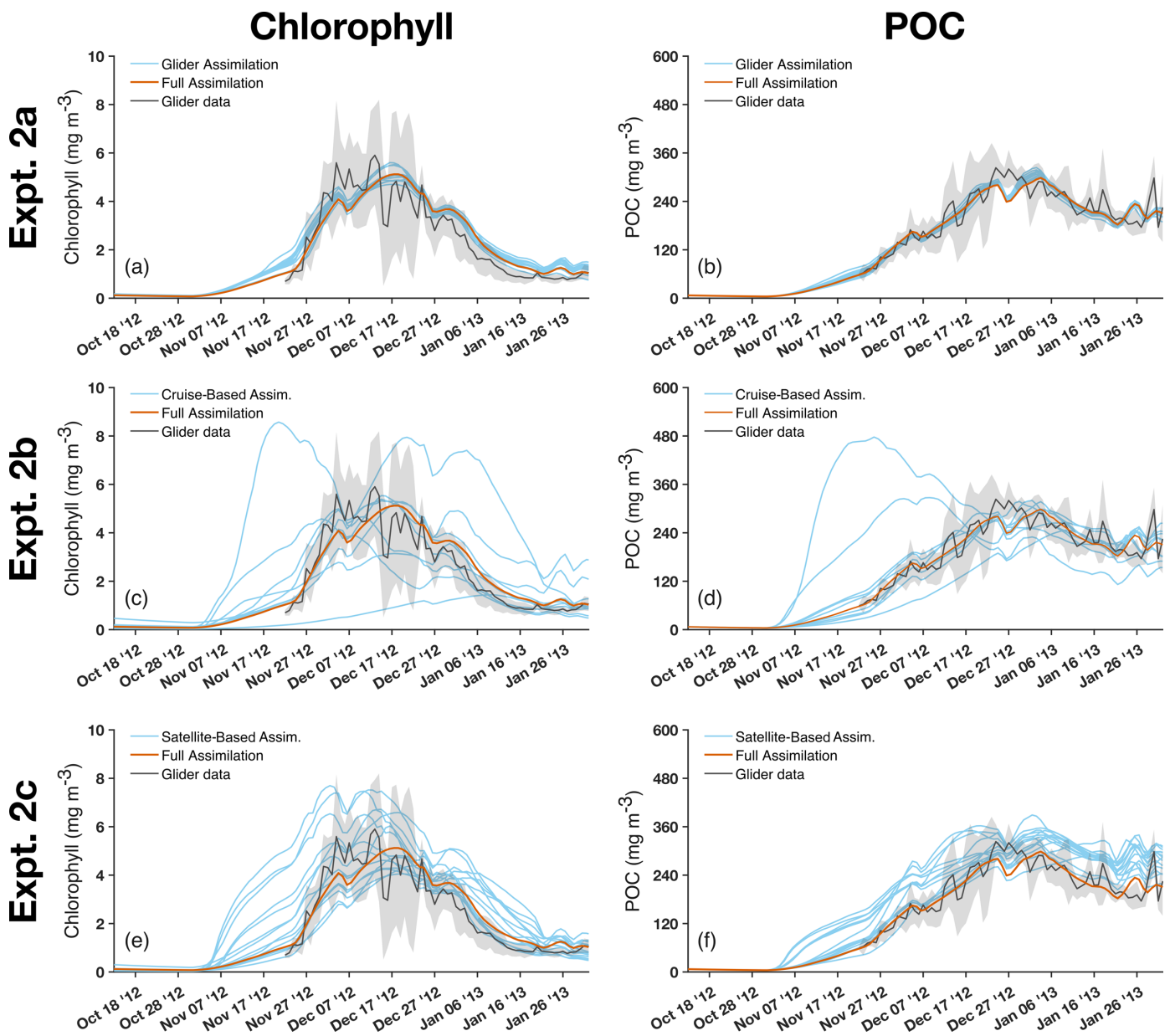

Figure 8. Upper $50 \mathrm{~m}$ mean concentrations of $(\mathbf{a}, \mathbf{c}, \mathbf{e}) \mathrm{Chl}$ and $(\mathbf{b}, \mathbf{d}, \mathbf{f})$ POC for various experiments assimilating subsets characteristic of the original glider data, cruise-based observations and satellite-based observations (Table 2): (a, b) Experiment 2a - glider observations; (c, d) Experiment $2 \mathrm{~b}$ - cruise-based observations; and (e, f) Experiment $2 \mathrm{c}$ - satellite-based observations. For reference, model results for the Full Assimilation case (orange lines) and glider data (black lines) with shading (gray) representing $1 \mathrm{SD}$ (from the upper $50 \mathrm{~m}$ ) are included in each panel.

Although both temporal and spatial gradients may be present, observations can be presented as either primarily spatial or temporal patterns with simple tests guiding the decision. For example, a comparison of means and SDs across spatial sections and time periods was previously used to identify time as the dominant dimension of variability in the 2012-2013 glider observations (Jones and Smith, 2017). In this study, a similar conclusion was reached, using a very different methodology. The assimilation of glider data from six different subareas of the study region (separated latitudinally or longitudinally by $\sim 20 \mathrm{~km}$ ) indicated that the seasonal cycle is similar in phase throughout the region of the glider track. The assimilation of glider data from each of the nine regions yielded similar estimates of POC and Chl, generally within the variance of the glider observations (gray areas of Fig. $5 \mathrm{c}-\mathrm{f}$ ), and similar estimates of temporally averaged primary productivity and export. This further supports the approach of using the glider data as a time series and suggests that temporal patterns on this scale play a greater role than spatial patterns in structuring variability in the phytoplankton assemblage. Moreover, the similarity between predictive and assimilative costs when assimilating the latitudinal and longitudinal bands of data suggests that the parameters are not being over-fit for these experiments. Thus, temporally resolved observations in any of these regions might be expected to provide similar constraints on modeled temporal patterns of the phytoplankton.

\subsection{Differences between assimilating glider, satellite-derived, and cruise-based data}

Results from experiments that assimilated data at different spatial and temporal resolutions suggest that assimilating only surface observations, as are typically available from remote-sensing platforms, underestimates carbon export and more weakly constrains estimates of productivity relative to 
the assimilation of depth-resolved glider data. The lower estimates of carbon export occurred because the optimal diatom fraction for fast-sinking detritus obtained via the assimilation of surface-only data $(0.62 \pm 0.14)$ was significantly lower than that obtained via the assimilation of data throughout the upper $50 \mathrm{~m}$ (Experiment 2a: $0.86 \pm 0.05$; Experiment $2 \mathrm{~b}: 0.86 \pm 0.11$ ). These results highlight the importance of assimilating subsurface measurements and of modeling diatom aggregation when estimating carbon export; similar findings were reported in 1-D biogeochemical optimization experiments using data from Lagrangian floats in the North Atlantic (Bagniewski et al., 2011). Experimental results also indicate that the assimilation of satellitederived data provides a weaker constraint on productivity estimates, as seen by the larger range of estimates (114 \pm $\left.11 \mathrm{~g} \mathrm{C} \mathrm{m}^{-2} \mathrm{yr}^{-1}\right)$, as compared to the assimilation of glider data $\left(104 \pm 2 \mathrm{~g} \mathrm{Cm}^{-2} \mathrm{yr}^{-1}\right)$. Although not statistically significant, the higher productivity estimates generated by the assimilation of satellite-derived data are consistent with those of Gregg (2008), who found that the assimilation of satellitebased chlorophyll estimates into a three-dimensional global biogeochemical model overestimated primary production. In contrast, results from assimilating satellite-derived chlorophyll concentrations into a one-dimensional model in the equatorial Pacific produced underestimates of primary productivity compared to in situ observations (Friedrichs, 2002).

Although both chlorophyll and POC were assimilated in the present study, chlorophyll alone has been the dominant satellite data product used in biogeochemical assimilation, although other data types are available and can impact the assimilation results. For instance, a study investigating the assimilation of different types of satellite-derived data, including POC and size-fractionated chlorophyll, found that the assimilation of satellite-derived POC estimates worsened the model estimates of chlorophyll, whereas the assimilation of chlorophyll did not substantially impact the POC estimates (Xiao and Friedrichs, 2014b). Additionally, satellite-based sampling bias could be reduced by concurrently assimilating export flux data derived from sediment trap measurements (Friedrichs et al., 2007) or by assimilating satellite measurements such as remote-sensing reflectance directly (Jones et al., 2016). It is also worth noting that when assimilating actual satellite data, the biases suggested by this study resulting from the assimilation of only surface data would be compounded with biases inherent in the satellite retrieval algorithms (Saba et al., 2011; Stukel et al., 2015).

Assimilating cruise-based data in the highly variable Ross Sea may also yield potentially large errors in primary production, as well as in carbon export estimates, depending on which specific days are sampled. Estimates of bloom timing from the assimilation of cruise-based observations may also vary substantially (Fig. 8c and d). This echoes the results of a series of reduced resolution data interpolations, from which Hales and Takahashi (2004) reported that cruise-based observations in the Ross Sea were likely able to capture average conditions well but miss some mesoscale phenomena. Likewise, a subsampling analysis of physical-biological correlations from 2010 Ross Sea glider data demonstrated the possibility of lower-resolution data obscuring or biasing biogeochemical interpretations (Kaufman et al., 2014). The results provided by the data assimilative study described here can be used to help guide decisions of when and how long to sample certain locations in the Ross Sea; this is especially important given the limitations of ship-based sampling in such a remote region (Smith et al., 2014). In fact, the use of data collection from other sampling platforms may decrease the pressure to conduct repeated transects by ship and allow limited vessel-time to be used for more thorough process-based investigations uniquely suited for research vessels.

\section{Summary and conclusions}

A series of experiments investigating spatiotemporal variability in the phytoplankton assemblage and potential effects of assimilating data from different observation platforms highlighted the benefits and challenges of combining data and biogeochemical models in the Ross Sea. The assimilation of glider data reduced model-data misfit by $50 \%$, and resulted in reduced depth-integrated primary production and higher carbon export at $200 \mathrm{~m}$. Additional experiments for different spatial regions reduced predictive costs with respect to unassimilated data by $\sim 35 \%$, suggested that the model parameters were well constrained, and implied that using glider data as time series in these local studies is a reasonable approach. This may further suggest the value of using moorings or buoys or even deploying gliders in a "virtual mooring" mode. However, the effects of mesoscale variability were apparent when assimilating data at a frequency characteristic of cruise-based sampling, which resulted in a wide range of primary production and export estimates depending on the sampling times. Results of assimilating data characteristic of satellite-based sampling suggest that assimilating satellite-derived data will result in underestimated carbon export. These findings can be used to help avoid potential sources of error when using ship-based or satellite-based observations alongside the development, calibration, or running of biogeochemical models. The combination of highresolution glider data and modeling in this study underscores the importance of considering how the timing at which observations are collected affects the subsequent interpretations. 
Appendix A: Latin hypercube sampling (Sect. 2.5.2)

Latin hypercube sampling (LHS) and Monte Carlo sampling are both techniques that can be used to randomly draw a finite number of samples from input distributions in order to approximate a full multidimensional distribution. The LHS incorporates stratified random sampling, i.e., in each dimension each sample is drawn randomly from within a different interval (also called a stratification or layer) of the distribution (McKay et al., 1979). Intervals are chosen with reference to the probability distribution such that each represents an equally probable range. In contrast, Monte Carlo sampling proceeds in each dimension with each sample drawn randomly from the entire distribution. Stratified random sampling with intervals of uniform probability ensures a good representation of the distribution, reducing the risk of samples being clustered in one or a small number of areas. In LHS sampling, if the sample size is $n$, each dimension is divided into $n$ intervals such that in multidimensional space each interval of each dimension is sampled once and once only. This is based on the idea of a Latin square in which an individual symbol appears once in each row and each column. It ensures that a good representation of the distribution is achieved for all dimensions. 
Data availability. Data from the autonomous glider are available from the BCO-DMO data repository (http://www.bco-dmo.org/ dataset/568868), and other data to support this article are available at W\&M Publish (https://doi.org/10.21220/V5RT5C) and upon request from the authors (dkauf42@gmail.com, marjy@vims.edu).

Competing interests. The authors declare that they have no conflict of interest.

Acknowledgements. This material is based upon work supported by the US National Science Foundation's Office of Polar Programs (NSF-ANT-0838980). The authors thank E. A. Canuel, E. E. Hofmann, and E. H. Shadwick for constructive comments. Additional thanks go to M. S. Dinniman for helping with model forcings. This work was performed (in part) using computational facilities at the College of William and Mary which were provided by contributions from the National Science Foundation, the Commonwealth of Virginia Equipment Trust Fund and the Office of Naval Research. This paper is contribution 3675 of the Virginia Institute of Marine Science, College of William and Mary.

Edited by: Marilaure Grégoire

Reviewed by: M. E. Gharamti and one anonymous referee

\section{References}

Arrigo, K. R. and McClain, C. R.: Spring phytoplankton production in the western Ross Sea, Science, 266, 261-263, https://doi.org/10.1126/science.266.5183.261, 1994.

Arrigo, K. R. and van Dijken, G. L.: Annual changes in sea-ice, chlorophyll $a$, and primary production in the Ross Sea, Antarctica, Deep-Sea Res. Pt. II, 51, 117-138, https://doi.org/10.1016/j.dsr2.2003.04.003, 2004.

Arrigo, K. R., Robinson, D. H., Worthen, D. L., Schieber, B., and Lizotte, M. P.: Bio-optical properties of the southwestern Ross Sea, J. Geophys. Res.-Oceans, 103, 21683-21695, https://doi.org/10.1029/98JC02157, 1998.

Arrigo, K. R., van Dijken, G. L., and Bushinsky, S.: Primary production in the Southern Ocean, 1997-2006, J. Geophys. Res., 113, 1-27, https://doi.org/10.1029/2007JC004551, 2008.

Asper, V. L. and Smith, W. O.: Particle fluxes during austral spring and summer in the southern Ross Sea, Antarctica, J. Geophys. Res., 104, 5345-5359, https://doi.org/10.1029/1998JC900067, 1999.

Asper, V. L. and Smith, W. O.: Abundance, distribution and sinking rates of aggregates in the Ross Sea, Antarctica, Deep. Res. Pt. I, 50, 131-150, https://doi.org/10.1016/S0967-0637(02)00146-2, 2003.

Bagniewski, W., Fennel, K., Perry, M. J., and D'Asaro, E. A.: Optimizing models of the North Atlantic spring bloom using physical, chemical and bio-optical observations from a Lagrangian float, Biogeosciences, 8, 1291-1307, https://doi.org/10.5194/bg8-1291-2011, 2011.

Bajpai, P. and Kumar, M.: Genetic algorithm - an approach to solve global optimization problems, Indian J. Comput. Sci. Eng., 1, 199-206, 2010.
Brent, R. P.: An algorithm with guaranteed convergence for finding a minimum of a function of one variable, in: Algorithms for Minimization Without Derivatives, 61-80, Prentice-Hall, Inc, 1973.

Črepinšek, M., Liu, S.-H., and Mernik, M.: Exploration and exploitation in evolutionary algorithms: a survey, ACM Comput. Surv., 45, 1-33, https://doi.org/10.1145/2480741.2480752, 2013.

DiTullio, G. R. and Smith, W. O.: Spatial patterns in phytoplankton biomass and pigment distributions in the Ross Sea, J. Geophys. Res., 101, 18467-18477, https://doi.org/10.1029/96JC00034, 1996.

Doron, M., Brasseur, P., Brankart, J.-M., Losa, S. N., and Melet, A.: Stochastic estimation of biogeochemical parameters from Globcolour ocean colour satellite data in a North Atlantic 3-D ocean coupled physical-biogeochemical model, J. Marine Syst., 117, 81-95, https://doi.org/10.1016/j.jmarsys.2013.02.007, 2013.

El-Sayed, S. Z., Biggs, D. C., Stockwell, D., Warner, R., and Meyer, M.: Biogeography and metabolism of phytoplankton and zooplankton in the Ross Sea, Antarctica, Antarct. J. US, 13, 131133, 1978.

Fennel, K., Losch, M., Schröter, J., and Wenzel, M.: Testing a marine ecosystem model: sensitivity analysis and parameter optimization, J. Marine Syst., 28, 45-63, https://doi.org/10.1016/S0924-7963(00)00083-X, 2001.

Fretwell, P., Pritchard, H. D., Vaughan, D. G., Bamber, J. L., Barrand, N. E., Bell, R., Bianchi, C., Bingham, R. G., Blankenship, D. D., Casassa, G., Catania, G., Callens, D., Conway, H., Cook, A. J., Corr, H. F. J., Damaske, D., Damm, V., Ferraccioli, F., Forsberg, R., Fujita, S., Gim, Y., Gogineni, P., Griggs, J. A., Hindmarsh, R. C. A., Holmlund, P., Holt, J. W., Jacobel, R. W., Jenkins, A., Jokat, W., Jordan, T., King, E. C., Kohler, J., Krabill, W., Riger-Kusk, M., Langley, K. A., Leitchenkov, G., Leuschen, C., Luyendyk, B. P., Matsuoka, K., Mouginot, J., Nitsche, F. O., Nogi, Y., Nost, O. A., Popov, S. V., Rignot, E., Rippin, D. M., Rivera, A., Roberts, J., Ross, N., Siegert, M. J., Smith, A. M., Steinhage, D., Studinger, M., Sun, B., Tinto, B. K., Welch, B. C., Wilson, D., Young, D. A., Xiangbin, C., and Zirizzotti, A.: Bedmap2: improved ice bed, surface and thickness datasets for Antarctica, The Cryosphere, 7, 375-393, https://doi.org/10.5194/tc-7-375-2013, 2013.

Friedrichs, M. A. M.: A data assimilative marine ecosystem model of the central equatorial Pacific: numerical twin experiments, J. Mar. Res., 59, 859-894, https://doi.org/10.1357/00222400160497544, 2001.

Friedrichs, M. A. M.: Assimilation of JGOFS EqPac and SeaWiFS data into a marine ecosystem model of the central equatorial Pacific Ocean, Deep-Sea Res. Pt. II, 49, 289-319, https://doi.org/10.1016/S0967-0645(01)00104-7, 2002.

Friedrichs, M. A. M., Hood, R. R., and Wiggert, J. D.: Ecosystem model complexity vs. physical forcing: quantification of their relative impact with assimilated Arabian Sea data, Deep-Sea Res. Pt. II, 53, 576-600, https://doi.org/10.1016/j.dsr2.2006.01.026, 2006.

Friedrichs, M. A. M., Dusenberry, J. A., Anderson, L. A., Armstrong, R. A., Chai, F., Christian, J. R., Doney, S. C., Dunne, J., Fujii, M., Hood, R., McGillicuddy Jr., D. J., Moore, J. K., Schartau, M., Spitz, Y. H., and Wiggert, J. D.: Assessment of skill and portability in regional marine biogeochemical models: role 
of multiple planktonic groups, J. Geophys. Res.-Oceans, 112, 122, https://doi.org/10.1029/2006JC003852, 2007.

Garrison, D. L., Gibson, A., Kunze, H., Gowing, M. M., Vickers, C. L., Mathot, S., and Bayre, R. C.: The Ross Sea Polynya Project: diatom- and Phaeocystis-dominated phytoplankton assemblages in the Ross Sea, Antarctica, 1994-1996, in Biogeochemistry of the Ross Sea, Antarct. Res. Ser., 78, 53-76, 2003.

Gharamti, M. E., Samuelsen, A., Bertino, L., Simon, E., Korosov, A., and Daewel, U.: Online tuning of ocean biogeochemical model parameters using ensemble estimation techniques: application to a one-dimensional model in the North Atlantic, J. Marine Syst., 168, 1-16, https://doi.org/10.1016/j.jmarsys.2016.12.003, 2017.

Gregg, W. W.: Assimilation of SeaWiFS ocean chlorophyll data into a three-dimensional global ocean model, J. Marine Syst., 69, 205-225, https://doi.org/10.1016/j.jmarsys.2006.02.015, 2008.

Gregg, W. W., Friedrichs, M. A. M., Robinson, A. R., Rose, K. A., Schlitzer, R., Thompson, K. R., and Doney, S. C.: Skill assessment in ocean biological data assimilation, J. Marine Syst., 76, 16-33, https://doi.org/10.1016/j.jmarsys.2008.05.006, 2009.

Hales, B. and Takahashi, T.: High-resolution biogeochemical investigation of the Ross Sea, Antarctica, during the AESOPS (US JGOFS) Program, Global Biogeochem. Cy., 18, 1-24, https://doi.org/10.1029/2003GB002165, 2004.

Hemmings, J. C. P. and Challenor, P. G.: Addressing the impact of environmental uncertainty in plankton model calibration with a dedicated software system: the Marine Model Optimization Testbed (MarMOT 1.1 alpha), Geosci. Model Dev., 5, 471-498, https://doi.org/10.5194/gmd-5-471-2012, 2012.

Hemmings, J. C. P., Srokosz, M. A., Challenor, P., and Fasham, M. J. R.: Split-domain calibration of an ecosystem model using satellite ocean colour data, J. Marine Syst., 50, 141179, https://doi.org/10.1016/j.jmarsys.2004.02.003, 2004.

Hemmings, J. C. P., Challenor, P. G., and Yool, A.: Mechanistic site-based emulation of a global ocean biogeochemical model (MEDUSA 1.0) for parametric analysis and calibration: an application of the Marine Model Optimization Testbed (MarMOT 1.1), Geosci. Model Dev., 8, 697-731, https://doi.org/10.5194/gmd-8-697-2015, 2015.

Hofmann, E. E. and Friedrichs, M. A. M.: Biogeochemical data assimilation, in: Encyclopedia of Ocean Sciences, edited by: Steele, J. H. et al., Elsevier, 364-370, 2001.

Hofmann, E. E. and Friedrichs, M. A. M.: Predictive modeling for marine ecosystems, in: The Sea, Volume 12: BiologicalPhysical Interactions in the Sea, edited by: Robinson, A. R., McCarthy, J. J., and Rothschild, B. J., John Wiley \& Sons, Inc., New York, 537-565, 2002.

Irby, I. D., Friedrichs, M. A. M., Friedrichs, C. T., Bever, A. J., Hood, R. R., Lanerolle, L. W. J., Li, M., Linker, L., Scully, M. E., Sellner, K., Shen, J., Testa, J., Wang, H., Wang, P., and Xia, M.: Challenges associated with modeling low-oxygen waters in Chesapeake Bay: a multiple model comparison, Biogeosciences, 13, 2011-2028, https://doi.org/10.5194/bg-13-2011-2016, 2016.

Jones, E. M., Baird, M. E., Mongin, M., Parslow, J., Skerratt, J., Lovell, J., Margvelashvili, N., Matear, R. J., Wild-Allen, K., Robson, B., Rizwi, F., Oke, P., King, E., Schroeder, T., Steven, A., and Taylor, J.: Use of remote-sensing reflectance to constrain a data assimilating marine biogeochemical model of the Great Barrier Reef, Biogeosciences, 13, 6441-6469, https://doi.org/10.5194/bg-13-6441-2016, 2016.

Jones, R. M. and Smith, W. O.: The influence of shortterm events on the hydrographic and biological structure of the southwestern Ross Sea, J. Marine Syst., 166, 184-195, https://doi.org/10.1016/j.jmarsys.2016.09.006, 2017.

Kane, A., Moulin, C., Thiria, S., Bopp, L., Berrada, M., Tagliabue, A., Crépon, M., Aumont, O., and Badran, F.: Improving the parameters of a global ocean biogeochemical model via variational assimilation of in situ data at five time series stations, J. Geophys. Res.-Oceans, 116, 1-14, https://doi.org/10.1029/2009JC006005, 2011.

Kaufman, D. E., Friedrichs, M. A. M., Smith, W. O., Queste, B. Y., and Heywood, K. J.: Biogeochemical variability in the southern Ross Sea as observed by a glider deployment, Deep-Sea Res. Pt. I, 92, 93-106, https://doi.org/10.1016/j.dsr.2014.06.011, 2014.

Kaufman, D. E., Friedrichs, M. A. M., Smith, W. O., Hofmann, E. E., Dinniman, M. S., and Hemmings, J. C. P.: Climate change impacts on southern Ross Sea phytoplankton composition, productivity, and export, J. Geophys. Res.-Oceans, 122, 2339-2359, https://doi.org/10.1002/2016JC012514, 2017a.

Kaufman, D. E., Friedrichs, M. A. M., Smith, W. O., Jr., Hofmann, E. E., Dinniman, M. S., Hemmings, J. C. P.: Associated Dataset: Climate Change Impacts on Southern Ross Sea Phytoplankton Composition, Productivity and Export, Virginia Institute of Marine Science, W \& M Publish, College of William and Mary, https://doi.org/10.21220/V5PC71, 2017b.

Kaufman, D. E., Friedrichs, M. A. M., Hemmings, J. C. P., and Smith Jr., W. O.: Associated Dataset: Assimilating biooptical glider data during a phytoplankton bloom in the southern Ross Sea, W \& M Publish, College of William and Mary, https://doi.org/10.21220/V5RT5C, 2017c.

Krishnakumar, K.: Micro-genetic algorithms for stationary and non-stationary function optimization, Proc. SPIE, 1196, 289, https://doi.org/10.1117/12.969927, 1990.

Lawson, L. M., Spitz, Y. H., Hofmann, E. E., and Long, R. B.: A data assimilation technique applied to a predator-prey model, B. Math. Biol., 57, 593-617, https://doi.org/10.1007/BF02460785, 1995.

Lawson, L. M., Hofmann, E. E., and Spitz, Y. H.: Time series sampling and data assimilation in a simple marine ecosystem model, Deep-Sea Res. Pt. II, 43, 625-651, https://doi.org/10.1016/09670645(95)00096-8, 1996.

Leonelli, S.: The impure nature of biological knowledge and the practice of understanding, in: Scientific Understanding: Philosophical Perspectives, Pittsburgh University Press, 1-27, 2009.

Li, Y., McGillicuddy Jr., D. J., Dinniman, M. S., and Klinck, J. M.: Processes influencing formation of low-salinity high-biomass lenses near the edge of the Ross Ice Shelf, J. Marine Syst., 166, 108-119, https://doi.org/10.1016/j.jmarsys.2016.07.002, 2017.

Little, H.: Quantifying spatial and temporal scales of phytoplankton variability in the Sub-Antarctic Ocean using a high-resolution glider dataset, Thesis, University of Cape Town, 2016.

Löptien, U. and Dietze, H.: Constraining parameters in marine pelagic ecosystem models - is it actually feasible with typical observations of standing stocks?, Ocean Sci., 11, 573-590, https://doi.org/10.5194/os-11-573-2015, 2015. 
Marsay, C. M., Sedwick, P. N., Dinniman, M. S., Barrett, P. M., Mack, S. L., and McGillicuddy Jr., D. J.: Estimating the benthic efflux of dissolved iron on the Ross Sea continental shelf, Geophys. Res. Lett., 41, 7576-7583, https://doi.org/10.1002/2014GL061684, 2014.

Matear, R. J.: Parameter optimization and analysis of ecosystem models using simulated annealing: a case study at Station P, J. Mar. Res., 53, 571-607, https://doi.org/10.1357/0022240953213098, 1995.

Mathot, S., Smith, W. O., Carlson, C. A., Garrison, D. L., Gowing, M. M., and Vickers, C. L.: Carbon partitioning within Phaeocystis antarctica (Prymnesiophyceae) colonies in the Ross Sea, Antarctica, J. Phycol., 36, 1049-1056, https://doi.org/10.1046/j.1529-8817.2000.99078.x, 2000.

McDonald, C. P., Bennington, V., Urban, N. R., and McKinley, G. A.: 1-D test-bed calibration of a 3-D Lake Superior biogeochemical model, Ecol. Modell., 225, 115-126, https://doi.org/10.1016/j.ecolmodel.2011.11.021, 2012.

McKay, M. D., Beckman, R. J., and Conover, W. J.: A comparison of three methods for selecting value of input variables in the analysis of output from a computer code, Technometrics, 21, 239-245, 1979.

Melbourne-Thomas, J., Wotherspoon, S., Corney, S., Molina-Balari, E., Marini, O., and Constable, A.: Optimal control and system limitation in a Southern Ocean ecosystem model, Deep. Res. Pt. II, 114, 64-73, https://doi.org/10.1016/j.dsr2.2013.02.017, 2015.

Mosby, A. and Smith, W. O.: Phytoplankton growth rates in the Ross Sea, Antarctica, Aquat. Microb. Ecol., 74, 157-171, https://doi.org/10.3354/ame01733, 2015.

Oschlies, A. and Schartau, M.: Basin-scale performance of a locally optimized marine ecosystem model, J. Mar. Res., 63, 335-358, https://doi.org/10.1357/0022240053693680, 2005.

Peloquin, J. A. and Smith, W. O.: Phytoplankton blooms in the Ross Sea, Antarctica: interannual variability in magnitude, temporal patterns, and composition, J. Geophys. Res., 112, 1-12, https://doi.org/10.1029/2006JC003816, 2007.

Powell, M. J. D.: An efficient method for finding the minimum of a function of several variables without calculating derivatives, Comput. J., 7, 155-162, https://doi.org/10.1093/comjnl/7.2.155, 1964.

Press, W. H., Teukolsky, S. A., Vetterling, W. T., and Flannery, B. P.: Numerical Recipes in C: The Art of Scientific Computing, 2nd Ed., Cambridge University Press, 1992.

Rudnick, D. L.: Ocean research enabled by underwater gliders, Annu. Rev. Mar. Sci., 8, 519-541, https://doi.org/10.1146/annurev-marine-122414-033913, 2016.

Saba, V. S., Friedrichs, M. A. M., Antoine, D., Armstrong, R. A., Asanuma, I., Behrenfeld, M. J., Ciotti, A. M., Dowell, M., Hoepffner, N., Hyde, K. J. W., Ishizaka, J., Kameda, T., Marra, J., Mélin, F., Morel, A., O'Reilly, J., Scardi, M., Smith Jr., W. O., Smyth, T. J., Tang, S., Uitz, J., Waters, K., and Westberry, T. K.: An evaluation of ocean color model estimates of marine primary productivity in coastal and pelagic regions across the globe, Biogeosciences, 8, 489-503, https://doi.org/10.5194/bg8-489-2011, 2011.

Schartau, M. and Oschlies, A.: Simultaneous data-based optimization of a 1-D-ecosystem model at three locations in the North Atlantic: Part II - Standing stocks and nitrogen fluxes, J. Mar. Res.,
61, 795-821, https://doi.org/10.1357/002224003322981156, 2003.

Schartau, M., Wallhead, P., Hemmings, J., Löptien, U., Kriest, I., Krishna, S., Ward, B. A., Slawig, T., and Oschlies, A.: Reviews and syntheses: parameter identification in marine planktonic ecosystem modelling, Biogeosciences, 14, 1647-1701, https://doi.org/10.5194/bg-14-1647-2017, 2017.

Schine, C. M. S., van Dijken, G., and Arrigo, K. R.: Spatial analysis of trends in primary production and relationships with largescale climate variability in the Ross Sea, Antarctica, J. Geophys. Res.-Oceans, 120,1-19, https://doi.org/10.1002/2015JC011014, 2015.

Schmitt, L. M.: Theory of genetic algorithms, Theor. Comput. Sci., 259, 1-61, https://doi.org/10.1016/S0304-3975(00)004060,2001

Sedwick, P. N., Marsay, C. M., Sohst, B. M., Aguilar-Islas, A. M., Lohan, M. C., Long, M. C., Arrigo, K. R., Dunbar, R. B., Saito, M. A., Smith, W. O., and DiTullio, G. R.: Early season depletion of dissolved iron in the Ross Sea polynya: implications for iron dynamics on the Antarctic continental shelf, J. Geophys. Res., 116, 1-19, https://doi.org/10.1029/2010JC006553, 2011.

Smith Jr., W. O.: Glider data from the southern Ross Sea collected from the iRobot Seaglider during the RVIB Nathaniel B. Palmer (AUV-SG-503-2012, NBP1210) cruises in 2012 (Penguin Glider project). Biological and Chemical Oceanography Data Management Office (BCO-DMO), dataset version 2015-1209. http://lod.bco-dmo.org/id/dataset/568868, 2015.

Smith, W. O. and Gordon, L. I.: Hyperproductivity of the Ross Sea (Antarctica) polynya during austral spring, Geophys. Res. Lett., 24, 233-236, https://doi.org/10.1029/96GL03926, 1997.

Smith, W. O. and Nelson, D. M.: Phytoplankton bloom produced by a receding ice edge in the Ross Sea: spatial coherence with the density field, Science, 227, 163-166, https://doi.org/10.1126/science.227.4683.163, 1985.

Smith, W. O., Nelson, D. M., and Mathot, S.: Phytoplankton growth rates in the Ross Sea, Antarctica, determined by independent methods: temporal variations, J. Plankton Res., 21, 1519-1536, https://doi.org/10.1093/plankt/21.8.1519, 1999.

Smith, W. O., Dinniman, M. S., Tozzi, S., DiTullio, G. R., Mangoni, O., Modigh, M., and Saggiomo, V.: Phytoplankton photosynthetic pigments in the Ross Sea: patterns and relationships among functional groups, J. Marine Syst., 82, 177-185, https://doi.org/10.1016/j.jmarsys.2010.04.014, 2010.

Smith, W. O., Shields, A. R., Dreyer, J. C., Peloquin, J. A., and Asper, V.: Interannual variability in vertical export in the Ross Sea: magnitude, composition, and environmental correlates, Deep-Sea Res. Pt. I, 58, 147-159, https://doi.org/10.1016/j.dsr.2010.11.007, 2011.

Smith, W. O., Tozzi, S., Long, M. C., Sedwick, P. N., Peloquin, J. A., Dunbar, R. B., Hutchins, D. A., Kolber, Z., and DiTullio, G. R.: Spatial and temporal variations in variable fluoresence in the Ross Sea (Antarctica): oceanographic correlates and bloom dynamics, Deep-Sea Res. Pt. I, 79, 141-155, https://doi.org/10.1016/j.dsr.2013.05.002, 2013.

Smith Jr., W. O., Goetz, K. T., Kaufman, D. E., Queste, B. Y., Asper, V., Costa, D. P., Dinniman, M. S., Friedrichs, M. A. M., Hofmann, E. E., Heywood, K. J., Klinck, J. M., Kohut, J. T., and Lee, C. M.: Multiplatform, multidisciplinary investigations of the impacts of Modified Circumpolar Deep Wa- 
ter in the Ross Sea, Antarctica, Oceanography, 27, 180-185, https://doi.org/10.5670/oceanog.2014.36, 2014.

Smith Jr., W. O., McGillicuddy, D. J., Olson, E. B., Kosnyrev, V., Peacock, E. E., and Sosik, H. M.: Mesoscale variability in intact and ghost colonies of Phaeocystis antarctica in the Ross Sea: distribution and abundance, J. Marine Syst., 166, 97-107, https://doi.org/10.1016/j.jmarsys.2016.05.007, 2017.

Song, H., Edwards, C. A., Moore, A. M., and Fiechter, J.: Data assimilation in a coupled physical-biogeochemical model of the California current system using an incremental lognormal 4-dimensional variational approach: Part 3 - Assimilation in a realistic context using satellite and in situ observations, Ocean Model., 106, 159-172, https://doi.org/10.1016/j.ocemod.2016.06.005, 2016.

St-Laurent, P., Friedrichs, M. A. M., Najjar, R. G., Martins, D. K., Herrmann, M., Miller, S. K., and Wilkin, J.: Impacts of atmospheric nitrogen deposition on surface waters of the western North Atlantic mitigated by multiple feedbacks, J. Geophys. Res. Ocean., 122, 8406-8426. https://doi.org/10.1002/2017JC013072, 2017.

Stukel, M. R., Kahru, M., Benitez-Nelson, C. R., Decima, M., Goericke, R., Landry, M. R., and Ohman, M. D.: Using lagrangianbased process studies to test satellite algorithms of vertical carbon flux in the eastern North Pacific Ocean, J. Geophys. Res.-Oceans, 120, 1-15, https://doi.org/10.1002/2015JC011264, 2015.

Thomalla, S. J., Ogunkoya, A. G., Vichi, M., and Swart, S.: Using Optical Sensors on Gliders to Estimate Phytoplankton Carbon Concentrations and Chlorophyll-to-Carbon Ratios in the Southern Ocean, Front. Mar. Sci., 4, 1-19, https://doi.org/10.3389/fmars.2017.00034, 2017.
Vaillancourt, R. D., Marra, J., Barber, R. T., and Smith, W. O.: Primary productivity and in situ quantum yields in the Ross Sea and Pacific Sector of the Antarctic Circumpolar Current, DeepSea Res. Pt. II, 50, 559-578, https://doi.org/10.1016/S09670645(02)00584-2, 2003.

Vallverdú, J.: What are simulations? An epistemological approach, Proc. Tech., 13, 6-15, https://doi.org/10.1016/j.protcy.2014.02.003, 2014.

Ward, B. A., Friedrichs, M. A. M., Anderson, T. R., and Oschlies, A.: Parameter optimisation techniques and the problem of underdetermination in marine biogeochemical models, J. Marine Syst., 81, 34-43, https://doi.org/10.1016/j.jmarsys.2009.12.005, 2010.

Xiao, Y. and Friedrichs, M. A. M.: Using biogeochemical data assimilation to assess the relative skill of multiple ecosystem models in the Mid-Atlantic Bight: effects of increasing the complexity of the planktonic food web, Biogeosciences, 11, 3015-3030, 10.5194/bg-11-3015-2014, 2014a.

Xiao, Y. and Friedrichs, M. A. M.: The assimilation of satellitederived data into a one-dimensional lower trophic level marine ecosystem model, J. Geophys. Res.-Oceans, 119, 2691-2712, https://doi.org/10.1002/2013JC009433, 2014b.

Yool, A., Popova, E. E., and Anderson, T. R.: Medusa-1.0: a new intermediate complexity plankton ecosystem model for the global domain, Geosci. Model Dev., 4, 381-417, https://doi.org/10.5194/gmd-4-381-2011, 2011. 